\title{
Business Re-engineering Strategic Process Model for Small-Medium Local Contractor's Sustainable Competitiveness: A Case of Tanzania
}

\author{
Ramadhani Said Tekka \\ Department of Construction Management and Technology, College of Architecture and Construction Technology, Mbeya University of \\ Science and Technology, Mbeya, Tanzania \\ Email address: \\ ramsotekka@yahoo.co.uk \\ To cite this article: \\ Ramadhani Said Tekka. Business Re-engineering Strategic Process Model for Small-Medium Local Contractor's Sustainable \\ Competitiveness: A Case of Tanzania. American Journal of Management Science and Engineering. Vol. 6, No. 4, 2021 , pp. 117-136. \\ doi: 10.11648/j.ajmse.20210604.15
}

Received: July 22, 2021; Accepted: August 20, 2021; Published: August 31, 2021

\begin{abstract}
Re-engineering the construction business process has been regarded as an acceptable management technique for reducing the overwhelmed construction challenges that have ascribed prolonged unsustainable competitiveness for most small and medium local construction firms in less developed countries. This study adopted the business re-engineering philosophy to identify and recommend the Strategic Business Process Model for the sustainable competitiveness of local firms in the domestic competitive environment. The questionnaire and in-depth interview survey were opted to collect the data from 227 respondents sampled through purposive sampling. SPSS 24-AMOS was used to analyze the data and create a structural equation model for sustainable competitiveness. The findings have revealed eleven (11) construction core and three (3) organizational process-related strategies, which suggest that the integration of design $(\beta 1=0.228, p=0.000)$, procurement $(\beta 2=0.091, p=0.003)$, construction management $(\beta 3=0.264, p=0002)$ and organizational $(\beta 4=0.068,00 ; p=0.004)$ strategic processes have proved a positive significant in attaining sustainable competitiveness of local firms. The study serves as a valuable empirical mark that provides insight and initial evidence for researchers, policy makers, and stakeholders in understanding potential construction core and organizational process strategies adopted by local firms to attain a competitive advantage.
\end{abstract}

Keywords: Small and Medium Local Contractor, Construction Processes, Business Process Re-engineering, Sustainable Competitiveness, Competitive Strategy

\section{Introduction}

The least developed countries (LDC) have envisaged Construction Industry (CI) as the most critical sector for their national economic development [1] as it represents a significant proportion of most countries' Gross Domestic Product (GDP). It provides essential infrastructures, including roads, airports, railways, buildings, schools, and hospitals, to mention a few. The constructed infrastructure performed by potential Small and Medium Local Contractors (SMLC) operating within several construction commercial business environments always enhances productivity performance and stimulates the development of other sectors for national economic growth [2]. Despite its vital significance to the LDC, the CI has faced different challenges led mainly by globalization and technology evolution which has removed borders and opened fast international construction trade growth. Thus, globalization has accelerated the competitive environment, i.e., struggle for construction market share and working opportunity among LDC and developed countries. To convert and intervene the internal and external environmental competitive effect, SMLC has opted to find and employ a dynamic and alternative strategic process and decision during business execution to attain sustainable competitiveness that will hold to maximize the profit and hence growth [3].

The introduction of Structural Adjustment Programmes (SAP) to LDC around the 1980s to 1990s instituted reducing 
or cutting off governments' investment funds. The effects led to a prolonged severe, and persistently shortage of Public funds [4]. Notwithstanding substantial investment in various construction infrastructures [5], the situation caused insufficient gross domestic saving for decades, resulting in an extended shortage of financial resources that could fund many public construction projects executed by many SMC [6]. This led to government withdrawal from direct provision of construction services and rendered to the private sector. Ultimately, the change in SAP's policy forced LDC to occupy a high-interest rate loan from industrialized economy countries under IMF and World Bank. The increase of interest rate witnessed by LDC had a catastrophic effect to the construction industry that led to the fell backward of many construction firms.

Nevertheless, only firms that continued to survive faced a highly competitive construction environment from overseas companies [7]. The competitive climate obstructed the growth of the local firm in terms of capability and unsustainable Competitiveness. However, the ongoing global business market has manifested an intensive international competition. The competition has triggered the need for local construction firms in LDC to find preferential strategies to respond and abide to increase clients' and stakeholders' demands to survive within the domestic hyper-competitive market. Currently, diverse construction firms have tried to identify their competitive market features to attain the competitive environment measured in achieving quality service or product at a lower or reasonable cost and within good delivery time [8]. The BPR technique has been viewed as necessary to scan, innovate, improve, and reengineer the strategic core construction business processes for SMLC to efficiently and effectively service delivery to serve the clients and customers better to attain sustainable competitiveness against the overseas firm. The "to be" re-engineered processes involve planning and engineering design, procurement, construction production management, and organizational/administration. Thus, this study intends to fill this gap.

\section{Literature Review}

\subsection{Overview of SME in Tanzania}

After its independence in 1961, Tanzania recognized to adopt the socialism and self-reliance strategic path for its national development. The state path aimed to capture and control all means of production after the nationalization of the critical private businesses venture [9]. This strategic approach recognized the increase and growth of social-economic development services, including water delivery, health services, and education. Nevertheless, the process occupied a negative consequence, leading to poor economic results in terms of financial crises and imbalances for some decades. The undesirable effect which embraced the emerged financial crisis manifested the need for an immediate transitional strategic policy change from a governmentally owned and controlled economy to a free-market economy. Thus, numerous initiatives were undertaken towards establishing the financial restructuring. Initiatives include a review of tax structure, reforms of the public sector, and trade liberalization. The liberalization led to an economic shift from a state-sectordriven economy to market liberalization [10]. Economic transformation enhanced the private sector (small and medium enterprises) establishment constituting over $90 \%$ of the economies and significantly acting as the potential driving force and an engine for the country's economic growth and creating millions of jobs.

The reviewed literature works have confirmed the absence of a universal definition of SME. The most denoted definition is grounded on repeatedly variables such as the number of employees, the capital invested, and annual income [11]. However, the recognized definition by various international organizations such as United Nations, European Union, World Trade Organization, and the World Bank varies with changes in the economy from one economic area to the other, as described in Table 1 below.

Table 1. SME Definitions Recognized by International Organizations.

\begin{tabular}{lllllll}
\hline \multirow{2}{*}{ Institution } & \multicolumn{5}{l}{ Number of Employees } & \multicolumn{4}{l}{ Turnover (EURO) } & \\
\cline { 2 - 7 } & Micro & Small & Medium & Micro & Small & Medium \\
\hline World Bank & $1-9$ & $<50$ & $50-249$ & Maximum $15,000,000$ & & \\
Asian Development Bank & \multicolumn{2}{l}{ No official definition, Apply, only definitions of individual national governments. } & \\
African Development Bank & $1-9$ & $\leq 50$ & NIL & NIL & & \\
EU & NIL & $<50$ & $50-249$ & $<€ 2$ Million & $<€ 10$ Million & $<€ 50$ Million \\
SADC \& ECOWAS & $0-9$ & $10-49$ & $50-249$ & NIL & & \\
Developed Countries & $0-9$ & $10-49$ & $50-249$ & $\leq €$ Million & $\leq € 10$ Million & $\leq € 43$ Million \\
\hline
\end{tabular}

In Tanzania, SMEs are described regarding the sector, investment capital, and the number of employees. A smallmicro enterprise incorporates 5 to 49 employees. It includes small shops, vendors, and merchants around the cities. A. medium enterprise covers 50 to 99 comprising a production or manufacturing, an industrial firm, and an exporting company. However, the capital investment ranges from less than 5Tshs million to over 100Tshs million. To ensure capacitating and exploiting of SMEs opportunities within a vibrant SME sector, Tanzania has initiated and instated the SMEs Policy aiming to empower multiple agencies and or Institutions such as Small Industries Development Organization. Moreover, it includes the Tanzania Trade Development Authority, Tanzania Bureau of Standards, Tanzania Private Sector Foundation, and other agencies established to support SMEs advancement [12]. Thus, in 
partnering with other development partners, including the United Nations Development Programme, the World Bank, and others, the country has envisaged soft-loan and various entrepreneurship training the most possible and potential strategy to permit a sustainable growth of SMEs.

When distinctly described reflecting the whether a construction project or sector, their development or growth involves multiple stakeholders, different phases with several processes occupied by other inputs as resources aiming to attain successful and sustainable competitiveness as a great aim of any particular firms. However, the firm's success in achieving its objectives profoundly depends on leadership quality, financial, technical, firm class, and organizational techniques employed by the firm [13]. In Tanzania, SMLC is classified into five groups (Table 2) and seven classes grounded on registration class limit, which describe the amount of the project's contract value limited to be tendered within a particular class range [14]. The class range depends and aims to designate the capabilities in terms of resources owned and controlled by the envisioned firm. Moreover, foreign firms are allowed to register only the two (I \&II) higher classes within the first four discipline groups and only three classes within the specialist contractor group. However, in building construction, it is worth to note that, class five are restricted to four (4) story structure, class six are limited to three (3) story structure. In contrast, class seven is not allowed to build any story structure [15].

Table 2. Classification of Contractor Enterprises in Tanzania.

\begin{tabular}{|c|c|c|c|c|c|}
\hline \multirow{2}{*}{$\begin{array}{l}\text { CLASS OF } \\
\text { REGISTRATION }\end{array}$} & \multicolumn{5}{|c|}{ A Group of Contractor and Class Limit for Single Contract (Million TZS) } \\
\hline & Civil Contractor & $\begin{array}{l}\text { Building } \\
\text { Contractor }\end{array}$ & $\begin{array}{l}\text { Electrical } \\
\text { Contractor }\end{array}$ & $\begin{array}{l}\text { Mechanical } \\
\text { Contractor }\end{array}$ & $\begin{array}{l}\text { Specialist } \\
\text { Contractor }\end{array}$ \\
\hline ONE & Unlimited & nlimited & Unlimited & Unlimited & Unlimited \\
\hline TWO & 8,000 & 5,000 & 3,000 & 3,000 & 800 \\
\hline THREE & 4,000 & 3,000 & 1,500 & 1,500 & 300 \\
\hline FOUR & 2,000 & 1,800 & 900 & 900 & \\
\hline FIVE & 1100 & 900 & 450 & 450 & \\
\hline SEVEN & 200 & 200 & 150 & 150 & \\
\hline
\end{tabular}

Sources: [15]

The general characteristics of SMLC as SME in most developing economies can be traced and grounded on their source of capital. Many SMLCs are believed to derive their start-up capital from the commercial bank since the loan is characterized by inequitable and discriminatory loan borrowing tight conditions and complicated regulations to access loans with a higher interest rate for the successful borrower. Because of socialism and close emotional motives such as love and faithfulness friendship, another SMLC opts free to acquire the capital from family and friends. In addition, Most SMLCs are described to operate within unstructured procedures, confronted with the erratic and inconsistent business strategic process with most oral communication rather than documentation. The situation has made resources allocation, market recognition, and expansion difficulties, which always maximize the probability of achieving the business endeavors and strengthening the firm operations. Moreover, the majority of SMLCs operate within rural and regional areas. The areas have inadequate infrastructure facilities such as insufficient and highly cost working premises, communication and transportation network facilities, serviced land warehouses, power problems with an inadequate supply, and unreliable and unrealistic costs [16].

Furthermore, SMLC is characterized by a lack of technical and competent staff, resources, management experts, and technology, which generally restrict their sustainable competitiveness. It was summarized by Sexton and Barrett [17] that SMLC is bounded and enclosed by four essential and unique characteristics, including inadequate financial resources, management skills, information sharing problems, and competent operatives. Consequently, it is recommended that, in
LDC's competitive market environment, SMLC, full of feeble and unproductive characteristics, needs to remain to strive to find a substitute technique against overseas firms for sustainable competitiveness.

Despite the presence of partnering and or joint-venture with overseas firms, SMLC in Tanzania has been recognized to facilitate the creation and provision of working opportunities, helping citizens to mobilize the investment capitals, to generate income for family subsistence, providing the income distribution to a majority that has significantly contributed to reducing poverty and hence led Tanzania to become a middle-income country by July 2020. Similarly, SMLC has played an essential social-economical role through directly influencing and stimulating every day's lives of most Tanzanian and participants to boost the development of the physical infrastructure involving the constructed commercial and residential building, transportation, and communication systems such as roads, highways, airports, shipment, electricity projects such as a 2115MW Rufiji Hydropower projects (one of Africa's largest hydropower dam) and an 1800km Standard Gauge Railway (SGR) linking Tanzania to neighboring counties. Thus, despite its significant importance, SMLC in Tanzania has attained a low level of growth for decades due to a prolonged poor delivery, which has led to unsustainable Competitiveness against an overseas firm in the domestic market. Thus, despite the increased number of registered firms, the rise in investment capital, as well as the rise in CI contribution to LDC GDP's, the market share of SMLC for both consultants and contractors in LDC's domestic market has remained very low [18]. Thus, it has resulted in a continual dependency of the LDC construction 
industry market on foreign firms which are sustainably competitive in the domestic and international market.

Numerous challenges have been noted to hinder SMLC's Competitiveness in LDCs. These include inadequate resources such as lack or shortage of technical and competent labor and finance or capital [19]. In addition, construction contract and claim problems, poor planning and management of formulated policy and strategy, low Gross Domestic Product (GDP), which reflects economic hardship and high level of poverty [20], poor historical performance, lack of advanced technology that improves product performance and poor government policy and support [21]. However, more challenges have been mentioned as Table 3 below provided a summarized holistic challenge facing SMLC in LD. The effects of the challenges have resulted in low performance, and unsustainable Competitiveness of SMLC measured in terms of cost of projects incurred (over budget), project's time extension without attaining value for money.

Table 3. A Summary of Challenges facing SMLC in Developing countries.

\begin{tabular}{|c|c|c|c|c|c|c|c|c|c|c|c|}
\hline \multirow{2}{*}{ Country } & \multicolumn{10}{|c|}{ Challenges } & \multirow{2}{*}{ Authors } \\
\hline & C1 & $\mathbf{C 2}$ & $\mathbf{C 3}$ & $\mathrm{C4}$ & $\mathbf{C 5}$ & C6 & C7 & C8 & C9 & $\mathrm{C10}$ & \\
\hline Tanzania & + & + & + & + & + & + & + & & + & + & (Tesha, D. N. et al., 2017; Kavishe, N. et al., 2019) \\
\hline Uganda & + & & + & + & + & + & + & + & + & + & (Ocen. S. J. et al., 2011; Basheka, B. C. et al., 2012) \\
\hline Kenya & + & & + & + & & + & & + & + & + & (Kenyatta, 2016; Momade, 2020) \\
\hline Zambia & + & + & + & + & + & + & + & + & + & + & (Chilongo Sylvia, C. and Mbetwa, S., 2017) \\
\hline Malawi & + & + & + & + & + & + & + & + & + & + & (Bentall, P. et al., 2020) \\
\hline Nigeria & + & & & + & + & & + & + & + & + & (Omopariola, D. E. et al., 2019; Akarowhe, 2018) \\
\hline Mozambique & + & + & + & + & + & + & + & + & + & + & (Nhabinde, V. et al., 2012; Cruz, A. S. et al., 2018) \\
\hline Botswana & + & + & + & + & + & + & + & + & + & + & (Ssegawa, 2013) \\
\hline Ghana & + & & + & & & + & & + & + & + & (Ardonceau, 2018; Marteye, N. T. et al., 2018) \\
\hline Swaziland & + & & + & + & + & + & & + & + & + & (Thwala, 2009) \\
\hline South Africa & + & + & & + & & + & + & & + & + & (Murray, M. and Apphia-Baiden, J., 2020) \\
\hline Zimbabwe & + & + & + & + & + & + & + & + & + & + & Thabani, N. and Wellington, G. B, 2017) \\
\hline
\end{tabular}

NOTE: C1-Finance/Capital; C2- Contractual challenges; C3-Shortage of local Skilled labor; C4-Lack of feasible government policies; C5-Lack of business experience; C6-Lack of modern technology; C7-Ineffective Competitiveness strategies; C8-Environmental Challenges; C9-Ethical and code of conduct (Malpractices); C10-Lack of training.

Various measures have been undertaken to increase the enterprise's market shares and uplift its competitive advantages. Measures include; establishment of agencies and institutions such as Tanzania Roads Agency (Tan Roads), National Housing Corporation (NHC), Contractors, Engineers, Architects and Quantity Surveyors Registration Boards (CRB, $\mathrm{ERB}$, and AQRB), formulation of SME policies, encouraging partnership and joint venture on construction projects, capacitating and strengthening construction sector related institution, the establishment of Public Procurement Act (PPA) and its regulation [22]. Moreover, it includes the establishment of CI policies of 2003, provision of various construction business training, reducing bureaucracy during registration, the establishment of Contractors Assistance Fund (CAF), adoption of short and long term plan together with the formation of ministries in government directly responsible with construction activities [23]. Despite the imposed efforts and measures, there still exist challenges facing SMLF that hinder sustainable competitiveness. However, the question remains, what are business re-engineering strategies for SMLC to attain sustainable competitiveness against overseas firms in the local construction market?

\subsection{Business Process Re-engineering (BPR)}

The effect of globalization, which led to a free market and increased business competition beyond borders, has compelled many construction firms to find an innovative system. The system has been considered as a solution approach to improve productivity and profits. It intended to reduce operating costs persistently increasing from one project to another, quality improvement in better service against complex and dynamic customer demands in domestic communities [24]. BPR has been adopted in this study to assist in identifying various strategic construction resources as inputs and processes as a competitive advantage to attain the drastic performance change of the firm. BPR allow construction firm to create value through potential processes, identify tangible resources, and value activities that can help firms circumvent the outdated traditions of doing business and adjust to adopt changes in their construction environment.

Most construction firms fail to understand, determine properly, or establish the correct, reasonable, and practical construction processes that lead to ineffective management failure to understand the way forward to attain sustainable competitiveness. It results in a redundancy business operation that led to wastage of resources, time, cost with poor end quality. In their study, Cheng and Tsai identified BPR as a philosophy that can be applied to develop a new rational construction management process to improve operational efficiency and increase the competitive ability of a construction firm. During the management of organizational change, Thyagarajan \& Khatibi recognized BPR to add a strategic value through the provision of new strategic vision, the building of operational capabilities, re-evaluation of new strategic options, and redefining the new products/services to reflect the firm's overall strategy [25]. Thus, BPR is strategically significant as it provides new hope and future direction for construction firms. Hammer and Champy defined Business process Re-engineering (BPR) as "the fundamental rethinking and radical redesign of business process to achieve dramatic improvement in contemporary 
critical measures of performance, such as cost, quality, service, and speed" [26]. Davenport and Short defined the term process as a set of logically interrelated tasks executed to attain some defined results [27].

A business process was described by [28] as a crowd of related tasks that create value. However, as coined by Shodhgang, 2008, BPR is a technique that involves restructuring, redesigning, and reengineering of the processes aiming to maximize an organization's potentials. It therefore assesses and creates an amendment of strategy, process, technology, organization, and culture of business within an organization [29], which leads to sustainable competitiveness. BPR is among the most popular strategic management techniques that have attracted much attention from business, manufacturers, and practitioners to bring tremendous organizational change. Thus, it is a tool or an approach adopted to transform through re-design and reshape to reduce the old and inefficient processes that can't deliver better business process results. BPR intends to reduce the operational cost; it aims to convert from sequential to simultaneous or parallel processes that rationalize the decision processes, accelerating increasingly sustainable competitiveness. Therefore, BPR uses resources to explore, adjust, and readjust the firm's activities, whether process or services that minimize delays, eliminate errors, reduce cost adaptable to the changing needs, and provide the firms with a competitive advantage.

BPR is a valued tool that has been applied as a substantial driver toward a dynamic change within many organizations. It was introduced to facilitate re-inventing the traditional system and practice of doing work. The term BPR was broken down into two components. "The letter B in BPR described the boundaries of a process that define a business value; the $\mathrm{P}$ in BPR defines "a primary focus on important processes that deliver outcomes in the signature of all variants of BPR rather than focus on static organizational structures [30]". BPR contributes significantly in changing the firms' process and behavior to become competitive, improve the capacity and capability, and satisfy customers, employees, and other stakeholders who wish for dramatic results that may help a firm survive in the long term [31]. Equally important, a Successful adoption/adaption of BPR has resulted in perceptible competitive benefits of firms through customer satisfaction, reducing cost, increased productivity, superior flexibility, and improved coordination. Generally, BPR incorporates a radical redesign that focuses on strategic processes that aim to attain a large firm's sustainable Competitiveness in reducing cost, timely delivery, and quality of service. BPR integrates the new strategic processes, re-design, and implementation of the changes in all its complex technological, human, and organizational diminutions" [32]. BPR has been used to describe what, how, and the results to be attained as a dramatic change. Table 4 provides a manifested chronological re-engineering definition, its principles, and the expected outcomes collected from various literature.

Table 4. A Chronological Order of Re-engineering Definition.

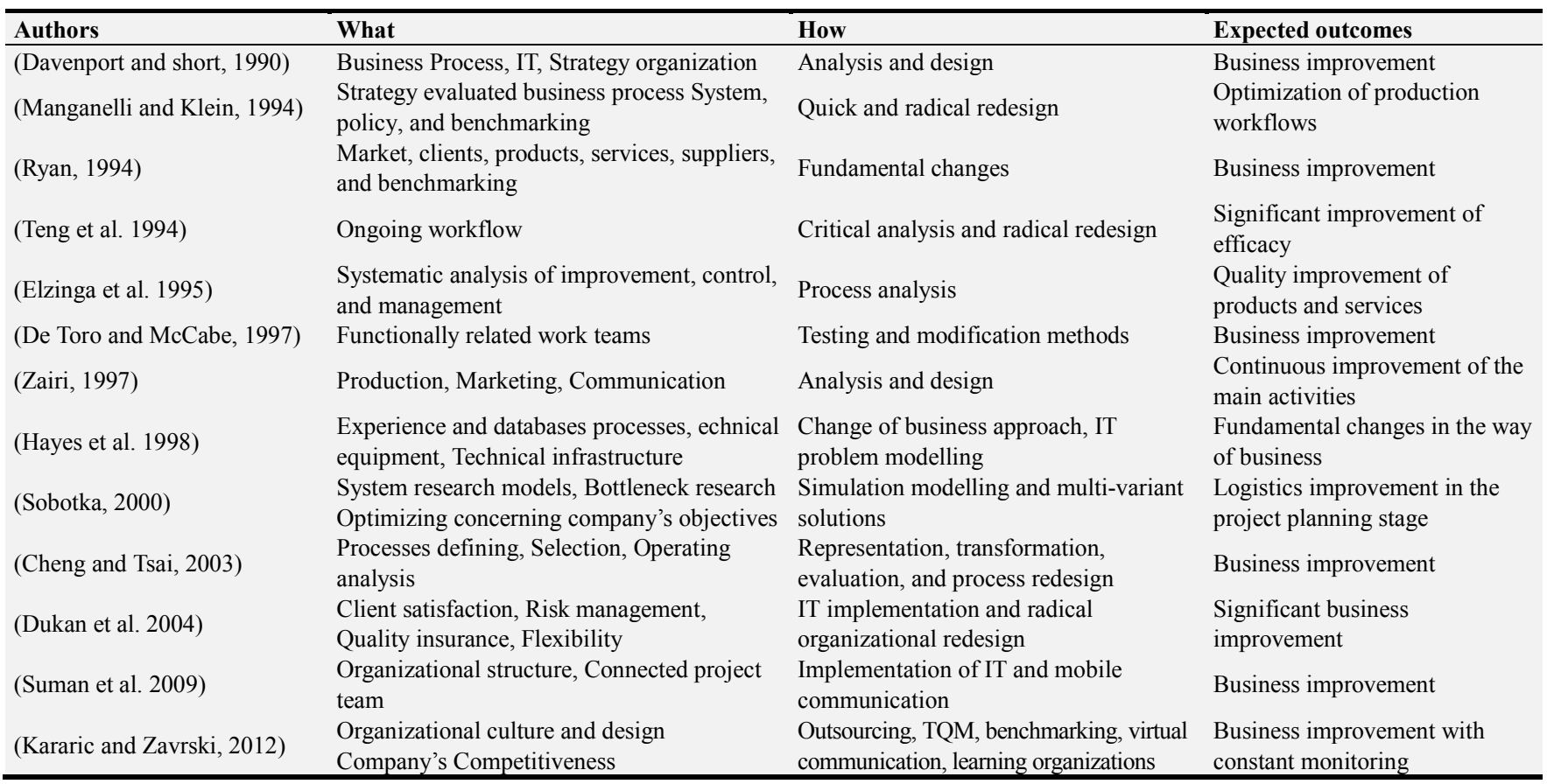

Source: Author; Extracted from Various Literature.

BPR has attained a low satisfactory level in CI due to its non-existence practically rather than in literature together with the uniqueness of the industry. Reasons mentioned for its nominal rate of adoption were non- implemented of the majority of re-engineered initiatives that indicated the resistance to change together with the uniqueness of the industry [33]. In addition, other reasons for its non-implementation in CI include the absence of 
systematic and collaborative processes that allow interface between varied process participants and lack of improvement efforts.

Thus, in this study, the BPR technique is adopted in helping SMLC in LDC to adapt, innovate, transform and remove unnecessary and remain with only core and value business processes as well as forming a flexible strategy and finding the government policies to efficiently serve the firms to attain sustainable competitiveness against overseas firms. Thus, from only three construction core and organizational processes identified above, only the core process will be successively designed to guarantee the best procedural value activities, maximize the control, increase operational efficiency to attain increased productivity, and improve sustainable performance competitiveness.

\subsection{A Conceptual Framework of the Study}

The framework of this study has adopted the business process re-engineering concept involving description and analysis of the re-engineering input attributes, including resources, processes, and policies to attain sustainable competitiveness as a dramatic change. The framework also indicates four strategic construction primary or core processes: design, procurement, construction production management, and organizational operations in attaining sustainable Competitiveness. However, a conceptual framework of the study (figure 1) provides the researcher's synthesis as referred to in previous literature in conjunction with the study philosophy to describe a phenomenon. The conceptual framework exposes the study variables (inputs and Processes) and the relationship between them to achieve sustainable competitiveness of SMLC of LDC.

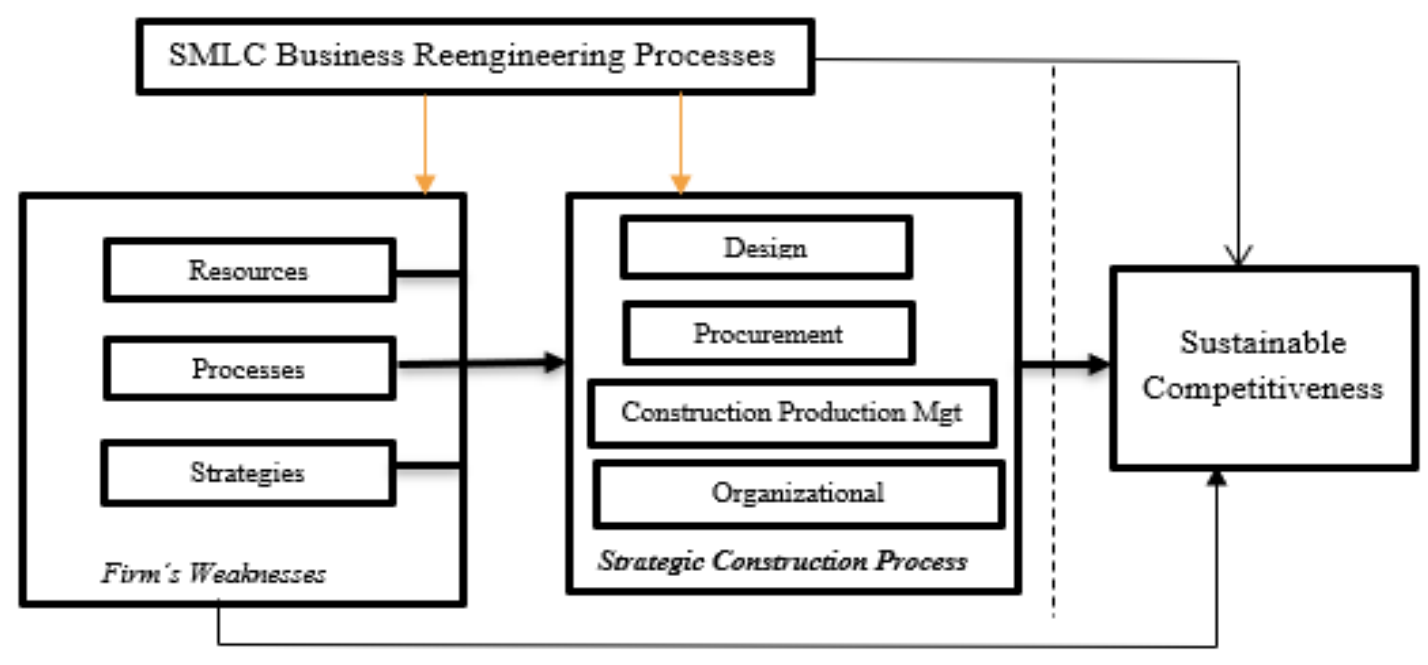

Figure 1. A Conceptual Framework of the Study.

\subsection{Sustainable Competitiveness}

Competitiveness is a continually worrying and debatable concept which have become open for many interpretations [34]. Therefore, the concepts can occupy different meanings regarding the particular context of literature used, whether firm, sector of economic activity of a specific region. The competitiveness concept has gained much interest to contractors and economists, politicians, industrialists, researchers, and academicians, reflecting developing and industrialized economy countries. The reviewed literature on the construction industry of LDC's Competitiveness has noted similar diagnoses for the prevailing challenges and the prescribed strategies for improving them. Thus, this paper aims to define the crystallized competitiveness strategies that rule the SMLC within LDCs. Flanagan justified the need for the study. et al. [35] that more research is required to help firms to formulate a competitive strategy. Thus, the published book titled "Competitive strategy" contributed expressively and rapidly the ever-increasing competitiveness concept [36]. Despite being a long-time concept to researchers in the academic and business industry, its definitions have failed to attain a universal consensus [37]. This has made an independent struggle from researchers for its definition. However, the struggle considered the competitive environment while aiming to improve the understanding of the phenomenon. Thus, it is evidenced that there is no consensus on a definition of Competitiveness [38].

Competitiveness can be defined reflecting the firm context as the ability of the firm to produce and deliver the suitable goods and or services of the right quality and price within the reasonable time to efficiently and effectively meet stakeholders and customers' requirements [39]. The ability assists the firm in competing effectively against other competitors. In addition, Competitiveness was described by the World Economic Forum (WEF) as "The set of institutions, policies, and factors that determine the level of productivity of a country. The level of productivity, in turn, sets the sustainable level of prosperity that can be earned by an economy" [40]. Nonetheless, several relevant attributes (s) can be extracted from the definition(s) for a more and broader understanding of the concept representing economics such as profitability, productivity or market share; a continuous improvement [41], realizing 
outcomes and objective, client satisfaction, innovation and value for shareholders as well as relative to competitors and allows the perception of potential. Thus, as ascribed, Competitiveness is a multi-defined, multi-measured, multilayered, dependent, relative, and dynamic derived as a management idea reflecting the economic indicators such as profitability, market share, and productivity to improve performance and Competitiveness [42].

Sustainable competitiveness can be defined as the set of institutions, policies, and factors that make a firm or a nation productive over a more extended period of time while ensuring social and environmental sustainability [43]. The history of sustainable Competitiveness was extended from sustainable development to encompass to put more emphasis than does on the importance of productivity as a driver of prosperity and long-term growth. Various important factors have been mentioned the drive to sustainable Competitiveness of either individuals, firms, sectors, or a country. The factors mentioned include capitals in the perspectives of productive capital, human resource capital, social, institutional capital, cultural capital, infrastructural capital, and knowledge/creativity capital [44]. In addition, (Suzanne Rosselet, 2011) declared financial, institutional, legal framework, infrastructure, innovation, and technology to attain sustainable competitiveness.

Moreover, Garelli, S. revealed four factors, including economic resources, government policy and efficiency, business efficiency (productivity, labor, management practice), and infrastructure (education and training and technology) [45]. Generally, to ascertain sustainable competitiveness within an organization, resources, feasible processes, and government policy and support are fundamental factors.

\subsection{Competitive Strategy Theory}

Two theories on Competitiveness developed by Porter portrayed the potential strategic area of Competitiveness. While the first theory adopted five competitive forces, including Strength, Weaknesses, Opportunity, Threats (SWOT), and Value chain [46], the second theory reflects the Resource Base View (RBV) of the firm [47]. The first theory describes the unique performance of the firm in executing similar activities compared to counterpart firms in attaining sustainable competitiveness. [48] Argued that competitive advantage is a crucial fundamental determinant of the firm's performance, which arises from either a protected market position or a specific (intangible resources), including knowledge and skills, leadership and culture, and a dynamic capability that involves periodic innovation.

The second theory describes the RBV of the firm as a collection of different resources together with value processes. Processes involve core competence, knowledge, and capability in transforming resources into economic profit [49] hence attaining better performance and sustainable Competitiveness. It was noted that if resources are possessed and effectively utilized by the firm, it becomes a fundamental source of competitive advantage. However, the two concept theories complement each other intending to realize competitive advantage [42]. From the above theory, it can be concluded that, only firm which can sustainably coordinate, controls, utilize more effectively and efficiently the available, valuable, rare, unique and non-substitutable resources, including all assets, competence and capabilities, value activities, firm attributes, information, knowledge can comprehensively implement the strategies compared to other competitor to attain a sustainable competitive advantage of the firm. Thus, this raises the need for identifying the resources as inputs and value process-related strategies as a substantial in achieving competitive advantage to SMLC to compete against the overseas.

A competitive strategy can be defined as a long-term plan to attain a competitive advantage for better performance and sustainable competitiveness against other competitors [50]. In achieving the competitive edge, Porter emphasized adopting the strategy, focus, differentiation, and low-cost leadership [51]. In construction, a differentiation strategy can be achieved through quality design that considers low construction costs to provide exceptional and valuable services to customers compared to other competitors. Focusing on cost reduction and control is the heart of costleadership strategy, making a firm attain profit and hence compete. Therefore, through experiences, different techniques should be applied to lower the cost while maintaining efficiencies. Techniques include reducing the operational, overhead, and R\&D expenses [51], and economical construction methods to facilitate attaining a sustainable competitive advantage.

Different competitive strategies that enable the firm to achieve sustainable competitiveness have been mentioned in various studies. These include; core competence management and the participation of every individual at all levels in the firm. This helps obtain the critical information that can assist in evaluation, identifying performance and competitiveness gap; hence, formulate an alternative strategy to fill the gap. A study conducted by Henny, A., and Mohammed, F. acknowledged that knowledge, technical competence, human resource, and conceptual skills are the essential strategies for a firm's sustainable Competitiveness [52]. Wang \& Yang proposed the strategic alliance as a fundamental strategy for firms to compete domestically or internationally [53].

Abd Ghani. et, al; recognized strategic planning and the international joint ventures as the essential elements and preferential strategies to be considered since they affect the daily operation of the firm [54]. The findings by Iyagba, R., \& Ojuola, J. coined the management competence as the best strategy for the sustained persistence and growth of the firms [55]. However, high investment in fixed assets also positively impacts the firm's ability to compete with some projects [56].

Furthermore, strategies identified include financial stability and partnership, firm owner's characteristics, human resource development and management, resource development, quality practice standards, and best construction method [57]. In the same vein, the government policy and support have acted as a potential and a preferred competitive strategy and catalyst. It plays a fundamental role as a client, promoter, and regulator in 
coordinating all undertakings towards successfully transforming a particular SMLC. However, Fajar (2017) have cemented the government support to facilitate creating a better business working environment, certifying training, capacitating the institution, and enforcing policy and strategies for the SMLC Sustainable Competitiveness [58].

Table 5. A Summarized Strategies for a Sustainable competitiveness.

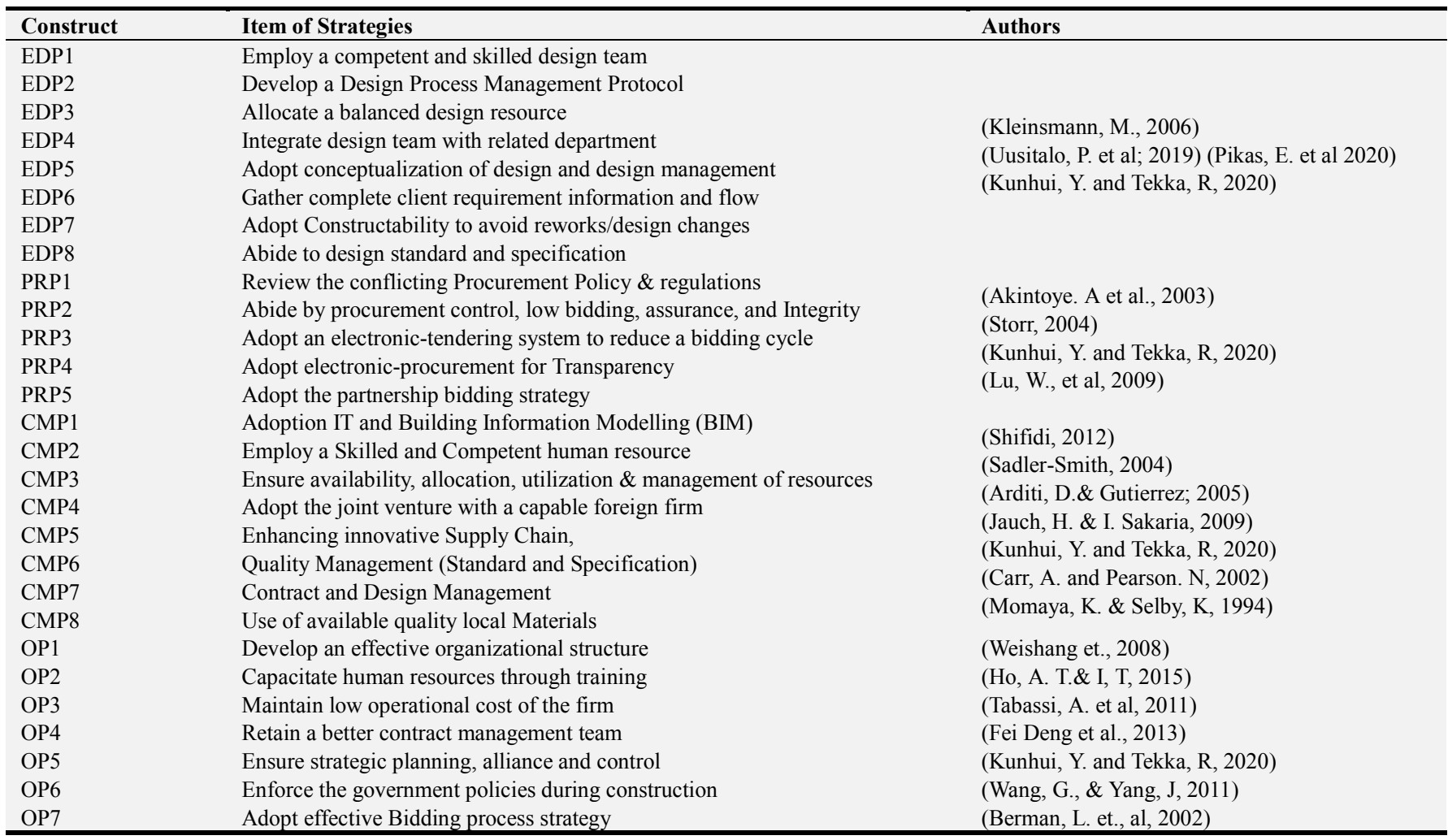

Note: ED=Engineering Design; $\mathrm{PR}=$ Procurement's=Construction management; $\mathrm{O}=$ Organizational; $\mathrm{P}=$ Process.

\section{Materials and Methods}

\subsection{Survey Method}

The study was conducted in Tanzania from December 2019 to June 2020. It adopted a questionnaire tool and an interview as a survey method to collect and assess a large population-based feature view on a small collected sample of respondents within the case study area representing LDCs. A total of (123) class one local firm [59] registered to Contactors Registration Boards (CRB) were identified. A good performance comprised good experience of more than ten years and the capability in terms of resources and experts as referred to their registration criteria. Since the study aimed to analyze the BPR strategies, only firms capable of undertaking and practicing, experienced, able to adopt, pay for undertaking the BPR training, and measure to analyze their performance to acquire sustainable competitiveness were considered. However, twenty (20) employees with more than ten years of experience were purposively selected from different firms for a pre-qualification interview of the systematic process. The pre-qualification of a systematic approach enabled the identification of thirty-one (31) firms with the BPR mentioned above capabilities with a total population of (519) conditioned to have a working experience of more than ten years. However, Taro Yamane's formula was applied in the equation below to compute the minimum sample size for the study resulted in (227) respondents.

$$
\text { Sample Size }(n)=\frac{N}{\left(1+N e^{2}\right.}=227
$$

Where " $n$ " is the minimum number of respondents required (minimum sample size), "N" is the study population size and "e" represent a level of precision, or an acceptable margin of error assumed at a $95 \%$ confidence level for this study [60]. Additionally, the study must test if the sample is adequate for Structural Equation Model (SEM) analysis. The online priori-sample size calculator for SEM

https://www.danielsoper.com/statcalc/calculator.aspx?id=89 ) was used in this study to find the minimum sample size. However, the anticipated effect size (Cohen's d) was 0.3. The desired statistical power level was 0.8 , the number of latent variables of the study was 4 , and the number of observed variables was 14 at the probability level of 0.05 . It was found that 138 is the minimum recommended sample size for SEM. Thus, this indicates that the above-calculated sample size (227) was suitable for the study and SEM analysis. 


\subsection{Questionnaire Design}

A structured questionnaire instrument divided into four parts was administered to registered respondents to obtain an opinion for the study. Part one aimed to obtain the respondent's demographic information. Part two is expected to get the views on the current dominant performance weaknesses of the firms. Part three intended to get information on the construction core and organizational process. Part four was focused on identifying the new potential process strategies under the business process reengineering philosophy embraced from the core construction and organizational Process.

A five binary Likert scale number (from $1=$ Strongly Disagree/Not Important/Not Influential, to $5=$ strongly Agree/ Very Important/Very Influential) planned to indicate the numerical ranks only were used. Neither absolute quantities nor equality interval between them was intended. A continuous average rating with proposed ordinal values helped precisely to translate the opinion results of respondents. The formula: (Highest Point minus Lowest Point in the Likert scale) Divide by the number of the levels was adopted to compute the level of each item [61]. However, the following group Likert scale points ( 1 to $\leq 1.8$ Represented Strongly Disagree); (1.81 to $\leq 2.6$ represented Disagree; [2.61 to $\leq 3.4$ described Moderate; ( 3.41 to $\leq 4.2$ represented Agree) and (4.21 $\leq 5$ expressed Strongly Agree) were used.

Twenty senior and experienced experts from previously identified respondents were randomly selected and registered for a pilot study. It was intended to test and identify mistakes, blunders, and incorrect, unnecessarily wordy, and unambiguous terms in the questionnaire. The pilot study facilitated to identify and review to produce a clear and elaborative questionnaire that every respondent could simply understand during questionnaire administering. A total of two hundred twenty-seven (227) copies of questionnaires written in English and translated into the local Swahili language were distributed. However, ethical consideration factors for respondents were considered, such as voluntarily or willingness to participate in the study, respondents anonymously completed the questionnaire, convenience for availability, accessibility to participate in the study. The researcher provided a brief clarification of the questionnaire during face-to-face interviews to ensure respondents understand the study objective. However, seventeen respondents who missed the face-to-face interview were communicated through their emails and social media networks such as WhatsApp, WeChat, and calls to fill in the questionnaire. One hundred eighty-nine (189) equivalent to (83.26\%) appropriately administered questionnaires were used for data analysis.

\subsection{Analysis Methods}

The collected sample data were coded, edited, descriptively analyzed, and checking for construct validity and reliability analysis using SPSS 24 and AMOS statistical software.
Construct validity was performed to measure the extent to which all items on a scale measure the same construct. Data reliability was examined to test the internal reliability of the 5-point Likert scale. The examination intended to check if the questionnaire survey tool provides equivalent results at different sets of tests. Besides, SPSS was used to perform the confirmatory factor analysis (CFA), whose result facilitated a convergent and discriminant validity test. However, using SPSS-AMOS, a structural Equation Modelling (SEM) was used to develop the sustainable competitiveness model.

\section{Results}

\subsection{Demographic Information}

The study respondents engaged $9.7 \%$ diploma graduate $57.3 \%$-degree graduate, $23.7 \%$-master graduate, and $9.3 \%$ PhDs. In addition, $61.7 \%$ represented engineers, $23.1 \%$ architects, $11.4 \%$ QS, and 3.8\% other experts. Furthermore, senior and experienced staff participated in the study. The respondents involved executive directors and general managers (23.1\%), construction project managers (33.4\%), section managers $(26.2 \%)$, and Site foremen and supervisors (17.3\%). However, the demographic characteristics of the respondents acknowledged the involvement of enough experts from SMLC who provided beneficial answers and constructive opinions as potential data for the study.

Table 6. Respondent's Demographic Information.

\begin{tabular}{llll}
\hline Item & Class & Frequency & Percentage (\%) \\
\hline & $18-30$ & 39 & 20.4 \\
Age (Years) & $31-43$ & 93 & 49.3 \\
& $44-56$ & 43 & 22.9 \\
Working & Above 56 & 14 & 7.4 \\
Experience & $10-20$ & 58 & 30.8 \\
(Years) & 21-30 & 97 & 51.3 \\
& Above 30 & 34 & 17.9 \\
Educational & Diploma & 18 & 9.7 \\
Level & Degree & 108 & 57.3 \\
& Masters & 45 & 23.7 \\
& PhD & 18 & 9.3 \\
& engineer & 116 & 61.7 \\
Professional & Architects & 44 & 23.1 \\
& Q. Surveyor & 22 & 11.4 \\
& Others & 07 & 3.8 \\
& Directors \& GMs & 44 & 23.1 \\
Leadership & PMs & 63 & 33.4 \\
& Section managers & 50 & 26.2 \\
& Foremen/Supervisor & 32 & 17.3 \\
\hline
\end{tabular}

\subsection{Competitiveness Weaknesses}

For the re-engineering process to occur, it was essential to understand the competitiveness weakness from either of the six-group category within competitive domestic markets as demonstrated by respondents. The relative importance index (RII) with Likert scale was opted to show the relative effects of the weakness on sustainable Competitiveness as represented below in (Table 7). Relative Importance Index was computed about the formula: Relative Importance Index $(\mathrm{RII})=\Sigma \mathrm{W} / \mathrm{AN}$ Where $\mathrm{W}$ defines the Likert scale weight (I- 
5) given to each weakness by respondents, A is the Likert scale highest score weight (5), and $\mathrm{N}$ is the total number of respondents (189). However, the most top-ten weaknesses were considered for explanation.

Table 7. Competitiveness Weaknesses.

\begin{tabular}{|c|c|c|c|c|c|c|c|c|c|c|}
\hline \multirow{2}{*}{ Weakness Category } & \multirow{2}{*}{$\begin{array}{l}\text { Weaknesses } \\
\text { Likert Scale Weight }\end{array}$} & \multicolumn{5}{|c|}{ Respondent's Frequency (N) } & \multirow{2}{*}{ Total N } & \multicolumn{2}{|r|}{ RII } & \multirow{2}{*}{ Ranking } \\
\hline & & 5 & 4 & 3 & 2 & 1 & & $\mathbf{\Sigma W}$ & $\Sigma W / A N$ & \\
\hline \multirow{4}{*}{ Client Related } & Lack of certified training & 63 & 59 & 47 & 11 & 9 & 189 & 723 & 0.765 & 10 \\
\hline & Late payment of completed works & 46 & 37 & 35 & 37 & 34 & 189 & 484 & 0.512 & 26 \\
\hline & Project interreference & 21 & 19 & 42 & 56 & 51 & 189 & 470 & 0.497 & 27 \\
\hline & Fail to abide to contract & 68 & 53 & 24 & 20 & 24 & 189 & 688 & 0.728 & 14 \\
\hline \multirow{3}{*}{ Consultant Related } & Late approval for payment & 56 & 49 & 44 & 23 & 17 & 189 & 671 & 0.710 & 15 \\
\hline & Poor \& late quality assurance/inspection & 79 & 79 & 19 & 5 & 7 & 189 & 549 & 0.581 & 23 \\
\hline & Fail to advice the client for good decision & 59 & 53 & 46 & 17 & 14 & 189 & 693 & 0.733 & 13 \\
\hline \multirow{6}{*}{ Contractor Related } & Inadequate financial ability & 89 & 79 & 21 & 0 & 0 & 189 & 824 & 0.872 & 2 \\
\hline & Poor resource management & 93 & 79 & 17 & 0 & 0 & 189 & 832 & 0.880 & 1 \\
\hline & Lack of modern technology & 68 & 62 & 51 & 8 & 0 & 189 & 757 & 0.801 & 7 \\
\hline & Inexperience & 71 & 59 & 43 & 11 & 5 & 189 & 747 & 0.790 & 9 \\
\hline & Shortage qualified and skilled employee & 81 & 67 & 36 & 3 & 2 & 189 & 789 & 0.835 & 5 \\
\hline & Use wrong construction method & 48 & 39 & 48 & 27 & 27 & 189 & 621 & 0.657 & 17 \\
\hline \multirow{2}{*}{ Government-Related } & Political Instability/interference & 29 & 46 & 57 & 39 & 18 & 189 & 596 & 0.631 & 19 \\
\hline & Non considerate regulations \& rules & 19 & 47 & 59 & 39 & 25 & 189 & 563 & 0.596 & 21 \\
\hline \multirow{5}{*}{$\begin{array}{l}\text { Professional \& } \\
\text { Ethical Related }\end{array}$} & Poor or frequently design changes & 52 & 69 & 41 & 14 & 13 & 189 & 700 & 0.741 & 12 \\
\hline & Predominantly Malpractices / Corruption & 81 & 67 & 28 & 6 & 7 & 189 & 776 & 0.821 & 6 \\
\hline & Non-adherence to standard \& specification & 49 & 49 & 54 & 23 & 14 & 189 & 663 & 0.702 & 16 \\
\hline & Inconsistencies in contract documents & 58 & 71 & 37 & 13 & 10 & 189 & 721 & 0.763 & 11 \\
\hline & Non-adherence to ergonomics principles & 19 & 37 & 71 & 47 & 15 & 189 & 565 & 0.598 & 22 \\
\hline \multirow{4}{*}{$\begin{array}{l}\text { Environmental } \\
\text { Related }\end{array}$} & Unforeseen conditions & 19 & 47 & 83 & 28 & 12 & 189 & 600 & 0.635 & 18 \\
\hline & Frequently weather changes & 43 & 41 & 39 & 29 & 37 & 189 & 591 & 0.625 & 20 \\
\hline & Conflicts/ Strike & 23 & 37 & 38 & 30 & 61 & 189 & 498 & 0.527 & 24 \\
\hline & Failure on waste management & 21 & 17 & 49 & 63 & 39 & 189 & 485 & 0.513 & 25 \\
\hline
\end{tabular}

Poor resource management was given the top priority since adequacy and poor management of resources invariably leads to project time extension, increases cost and unsatisfactory quality, and becomes unprofitable, one of the potential factors of Competitiveness. Resources are one of the primary influential and competitive advantages for any firms' progression. Thus, SMLC is encouraged for resource management to attain sustainable competitiveness against overseas firms. Moreover, financial inability to SMLC was secondly ranked. Many firms agreed to face the economic calamities and challenges from the financial institutions. As per respondents, firms are confronting with unnecessary bureaucracy in accessing loans. Despite the bureaucracy, most financial institutions have imposed high-loan interest rates that mostly require a non-movable property as collateral for the loan.

Furthermore, the absence of feasible, practicable, and viable competitive strategies and realistic government policy and support to SMLC from LDC have failed firms to attain the ability to outperform their rivals. The government needs to establish and emphasize construction strategies and policies which will facilitate sustainable competitiveness. Inexperience among unskilled labor has simultaneously hindered sustainable competitiveness.

Most SMLC employs inexperienced, unskilled, and fresh graduate labor expecting to pay them little. It hinders the performance and hence Competitiveness. Not only was that, but also inadequate infrastructure supervision mentioned among the priority weakness to hinder Competitiveness as it leads to project delay. In addition, another drawback includes a lack of certified training. Many SMLC has no on-job training culture. This has made most employees fail to strengthen their skills, hence failing to reduce the weak link among employees during work execution. Thus, it is advised to have a staff development program through on-job training to improve their performance to become competitive. In the same vein, most respondents cautioned the predominant malpractices, especially corruption behavior during tendering and construction. The attitude has caused awarding the work to unqualified, incompetent, and unskilled firms that eventually fail to compete within the market, leading to inadequate or incomplete construction projects.

\subsection{Characteristics of SMLC}

Understanding the characteristics of SMLC is important and a key for a dramatic change to improve Competitiveness. The identification of the firm attribute intended for BPR was among the vital stage of the study. Using descriptive analysis, the average mean for characteristics was computed. Only those attained above the stated five Likert scales range (3.41-Agree or effective to 5-strongly agree/effective) were considered the potential characteristics for SMLC's sustainable Competitiveness. However, the findings realized eight (8) characteristics. Quality resource availability $(\mathrm{M}=4.51$; $\mathrm{SD}=0.931$ ) was first ranked to facilitate the $\mathrm{SC}$ of the firm. The best management practice $(\mathrm{M}=4.47 ; \quad \mathrm{SD}=0.913)$ and competent, skilled, and experienced employees $(\mathrm{M}=4.33$; 
$\mathrm{SD}=1.004)$ were noted to facilitate attaining a dramatic change to attain a SC. Other characteristics includes proper organization process $(\mathrm{M}=4.09 ; \mathrm{SD}=0.825)$, proper information sharing $(\mathrm{M}=4.01 ; \mathrm{SD}=0.775)$ and ethical practices $(\mathrm{M}=3.92$; $\mathrm{SD}=0.827)$. However, realistic and visionary strategies for the firm $(\mathrm{M}=3.87 ; \quad \mathrm{SD}=0.867)$ were coined to facilitate benchmarking the key management facets and change the market structures and the rules of competition. Nevertheless, adherence to professional ethics and code of conduct was last mentioned as a moral consideration which helps to treat the construction project's process equally with the same degree of honesty as stated in contract documents to attain a successful re-engineering process and hence a SC.

Table 8. The Characteristics of SMLC.

\begin{tabular}{lllll}
\hline Code & SMLC Characteristics & Mean & Std. Deviation & Skewness \\
\hline A & Quality resource availability & 4.51 & 0.931 & 0.254 \\
B & Best management practice & 4.47 & 0.913 & 0.406 \\
C & Competent, skilled and experienced employees & 4.33 & 1.004 & 0.266 \\
D & Proper organizational processes & 4.09 & 0.825 & 0.543 \\
E & Proper information \& communication channel & 4.01 & 0.775 & 0.528 \\
F & Ethical consideration & 3.92 & 0.827 & 0.377 \\
G & Presence of realistic \& visionary strategies & 3.87 & 0.867 & 0.353 \\
H & Adherence to professionalism & 3.74 & 0.806 & 0.767 \\
\hline
\end{tabular}

\subsection{Strategy Identification and Ranking}

From the literature, various construction core strategic processes together with organizational process strategies were identified. At first, SPSS-24 was used to compute Cronbach's alpha coefficient to assess and measure the reliability and internal consistency of four latent variables (items). The Cronbach's coefficient indicates the covariance between the pairs of objects. However, it can be seen from
Table 9 that the computed value was found to be within the acceptable value of 0.7 [62]. Secondly, Kaiser-Meyer-Olkin (KMO) measuring the Sample adequacy was computed using the Principle Component Analysis (PCA) method. The result analysis revealed the chi-square of approximately $\left(\chi^{2}\right.$ $=2365.22), \quad(\mathrm{DF}=861.7)$ and $\mathrm{KMO}(0.772)$ at $(0.000)$ significant level. The result indicates a non-identity correlation matrix that suggests the samples' suitability or factor analysis [63].

Table 9. Cronbach's Alpha Coefficient.

\begin{tabular}{|c|c|c|c|c|}
\hline \multirow{2}{*}{$\begin{array}{l}\text { Item } \\
\text { Manifested Variables }\end{array}$} & \multicolumn{4}{|c|}{ Construction Processes (Latent Variables) } \\
\hline & Design & Procurement & Construction Prod.Mgt & Organizational \\
\hline No. of Observed Variables & 4 & 3 & 4 & 3 \\
\hline Cronbach's alpha coefficient & 0.915 & 0.794 & 0.767 & 0.711 \\
\hline
\end{tabular}

Furthermore, the descriptive analysis and a one-sample -ttest of strategies were computed to obtain the mean score. Using SPSS, a descending mean score, standard deviation, Tvalues and confidence interval (CI) of each strategy (Table 9) facilitated ranking of fourteen strategies (14) whose scores were above the acceptable stated value of 3.41, implying important or effective and considered to facilitate an SC of SMLC. However, if two or more strategies fall within the same scale mean value, the one with a lower standard deviation was highly ranked.

Table 10. Ranking of Strategy.

\begin{tabular}{|c|c|c|c|c|c|c|c|}
\hline \multirow{2}{*}{ Strategies } & \multirow{2}{*}{ Mean } & \multirow{2}{*}{ Std. Deviation } & \multirow{2}{*}{ T-Values } & \multicolumn{2}{|c|}{ 95\% Confidence } & \multirow{2}{*}{ Skewness } & \multirow{2}{*}{ Kurtosis } \\
\hline & & & & Lower & Upper & & \\
\hline CMP3 & 4.22 & 1.24 & 33.928 & 3.973 & 4.4668 & -0.43 & -0.65 \\
\hline CMP2 & 3.99 & 1.33 & 30.011 & 3.726 & 4.253 & -0.38 & -0.57 \\
\hline CMP1 & 3.85 & 1.31 & 29.489 & 3.590 & 4.109 & -0.33 & -0.49 \\
\hline $\mathrm{OP} 2$ & 3.83 & 1.62 & 23.629 & 3.508 & 4.151 & -0.55 & -0.96 \\
\hline PRP3 & 3.81 & 1.41 & 26.982 & 3.529 & 4.090 & -0.31 & -0.51 \\
\hline OP1 & 3.75 & 1.65 & 22.760 & 3.423 & 4.076 & -0.38 & -1.17 \\
\hline EDP3 & 3.72 & 1.48 & 25.060 & 3.425 & 4.014 & -0.34 & -0.75 \\
\hline CMP4 & 3.69 & 1.30 & 28.509 & 3.436 & 3.950 & -0.27 & -0.52 \\
\hline EDP4 & 3.66 & 1.52 & 24.094 & 3.358 & 3.961 & -0.23 & -0.95 \\
\hline EDP1 & 3.60 & 1.46 & 24.601 & 3.309 & 3.890 & -0.36 & -0.90 \\
\hline PRP1 & 3.53 & 1.53 & 23.014 & 3.225 & 3.834 & -0.04 & -0.82 \\
\hline PRP2 & 3.50 & 1.40 & 25.067 & 3.223 & 3.777 & -0.09 & -0.74 \\
\hline EDP2 & 3.50 & 1.56 & 22.432 & 3.190 & 3.809 & -0.26 & -1.02 \\
\hline OP3 & 3.43 & 1.80 & 18.428 & 2.953 & 3.666 & 0.11 & -1.35 \\
\hline
\end{tabular}

The first three highly ranked strategies with mean, Std deviation, T-values, and CI (Table 10) represent the construction management-related strategies. They include; ensuring effectively availability, allocation, proper utilization 
\& management of all resources during construction ensure availability and employment of skilled, Competent and experienced human resource together with adoption and use of IT and Building Information Modelling (BIM) which saves time and cost of delivering the quality performance which are competitive advantages to SMLC to attain a SC. Resources include skilled workforce, finance, technology, equipment, materials, environment, and fixed assets such as land, real estate, and leadership. However, the fixed assets can act as a resource to be used as collateral security of the firm when applying for a loan on financial institutions [64]. Another strategy mentioned is the adoption of the joint venture with a capable foreign firm. Working in collaboration with foreign firms was noted to facilitate sharing skills, expertise, resources, and technology to create a competitive advantage. Thus, it is proposed that the government enforce laws on a joint venture in some public projects to assist SMLC in learning different strategies adopted by experienced foreign firms that help in problem-solving.

An organizational process including training to capacitate employees were also prioritized in the list. A certified training was noted to enhance knowledge sharing to an employee. Training not only acts as recognition and rewards to an employee but also serves as a firm's competitive advantage [65]. However, respondents witnessed most of the firm owners in LDC to possess only financial power rather than knowledge and skills. During a face-to-face interview with one of the firm owners, it was noted that "Money is everything, whenever owning money, nothing more is required." He insisted that "a firm owner can do whatever possible to win the tender and engage an expert for project execution." Thus, lack of knowledge and skills to firm owners and stakeholders has made unsustainable growth and in Competitiveness of SMLC. Training constitutes strategies, policies, procedures, lessons, and tools for higher productivity, better performance, and SC [66]. Therefore, onjob training, seminars, and workshops must be enforced by the government and conducted to share knowledge and skills. Other organizational strategies mentioned involves: developing an effective organization structure for the firm and maintaining low operational cost.

The adoption of an electronic-tendering system was mentioned to reduce the bidding cycle during construction. This helps contractors shorten the process to acquire the resources quickly and efficiently to facilitate a proper supply chain. As noted by Lu, W. et al., 2009, the bidding strategy significantly impact the firm's Competitiveness [67]. Despite the Public Procurement Act (PPA, 2001), which emphases the lowest bidder to be awarded a contract, many SMLC has no proper bidding strategy during bidding and construction compared to foreign firms. However, SMLC needs to think strategically and develop a competitive bid with reasonable profit, which in turn can have the possibility of winning the tender. Therefore, firms need to strategize on bidding as influenced by different factors, including policy, firm goals, etc. Thus, it is proposed to SMLC to reduce unnecessary cost, resulting in high costs imposed during the bidding process.

The practical design strategy was also coined to facilitate a SC. They include: effective allocation of a balanced design resource, developing a Design Process Management Protocol (DPMP), employing a competent and skilled design team, and integrating the design team with another related department [68]. Engineering design engages several interactive, intellectual, and management skills or competencies such as teamwork, communications, decisionmaking, problem-solving, processing core professional field and general knowledge competencies bundles [69].

\subsection{Potential Sustainability Competitiveness Strategies}

To obtain the potential sustainability competitiveness strategies, the factor analysis technique was opted to assist in recognizing a comparatively small number of uncorrelated observed variables with correlated patterns of response. At first, principal component analysis was conducted to reduce the observed variables into a small correlated group of variables. The results yielded four groups with fourteen strategies whose factor loading owned the acceptable value and have met the requirement for a good model fit with KMO value of (0.715) and $(\chi 2$ /degree of freedom $=732.805 / 299$. However, the data were proved to be adequate for the factor analysis process. (Table 11) provides the factor analysis results with varimax rotation. The analysis delivered the cluster matrix with a pattern of fourteen potential uncorrelated strategies having the eigenvalues above the digit and total variance of approximate $(74.59 \%)$. On top of that, the composite reliability and the average variance extracted (AVE) of each construct was computed with values found to be above the acceptable value of $(0.7$ and 0.5$)$ respectively [70]. The findings of (Table 12) suggests the presence of a related discriminant validity between construct variables.

Table 11. A Rotated Component Matrix of Potential Sustainability Competitive Strategies.

\begin{tabular}{llll}
\hline \multirow{2}{*}{ Code } & Strategies & Clusters & \\
\cline { 3 - 4 } & & $\mathbf{1}$ & $\mathbf{2}$ \\
\hline EDP1 & Employ a competent and skilled design team & 0.921 & $\mathbf{4}$ \\
EDP2 & Develop a Design Process Management Protocol & 0.859 & \\
EDP3 & Allocate a balanced design resource & 0.894 & 0.818 \\
EDP4 & Integrate design team with related department & 0.931 \\
PRP1 & Review the conflicting Procurement Policy \& regulations & 0.871 \\
PRP2 & Abide to procurement control, low bidding, assurance and Integrity & 0.693 \\
PRP3 & Adopt an electronic-tendering system to reduce a bidding cycle & 0.901 \\
CMP1 & Adoption IT and Building Information Modelling (BIM) & 0.799 & 0.736 \\
\hline
\end{tabular}




\begin{tabular}{|c|c|c|c|c|c|c|c|}
\hline \multirow{2}{*}{ Code } & \multirow{2}{*}{ Strategies } & \multicolumn{6}{|c|}{ Clusters } \\
\hline & & 1 & 2 & 3 & 4 & $\mathbf{C R}$ & AVE \\
\hline CMP2 & Employ a Skilled and Competent human resource & & & 0.941 & & & \\
\hline CMP3 & Ensure availability, allocation, utilization \& mgt of resources & & & 0.905 & & 0.971 & 0.866 \\
\hline CMP4 & Adopt the joint venture with capable foreign firm & & & 0.993 & & & \\
\hline OP1 & Develop an effective organization structure & & & & 0.597 & & \\
\hline OP2 & Capacitate human resource through training & & & & 0.867 & 0.957 & 0.852 \\
\hline \multirow[t]{6}{*}{ OP3 } & Maintain low operational cost of the firm & & & & 0.887 & & \\
\hline & NOTE: 1. Extraction Method: PCA & & & & & & \\
\hline & 2. Rotation Method: Varimax rotation & & & & & & \\
\hline & 3. Initial Eigen Values & 4.141 & 2.206 & 1.757 & 1.593 & & \\
\hline & 4. Percentage of Variance $(\%)$ & 31.851 & 16.967 & 13.512 & 12.256 & & \\
\hline & 5. Cumulative percentage of initial Eigenvalues & 31.851 & 48.818 & 62.329 & 74.586 & & \\
\hline
\end{tabular}

However, as commented by Hair. J. et. al, the square root of the AVE diagonal (Table 11) of the latent variables indicates the highest value in any column. The findings identified the presence of discriminant validity of the data that provides a strength to allocate each item on the specified latent construct.

Table 12. Discriminant Validity.

\begin{tabular}{lllll}
\hline & EDP & PRP & CMP & OP \\
\hline EDP & 0.912 & & & \\
PRP & 0.733 & 0.889 & & \\
CMP & 0.681 & 0.675 & 0.853 & 0.817 \\
OP & 0.781 & 0.597 & 0.743 & \\
\hline
\end{tabular}

$\mathrm{EDP}=$ Engineering Design; $\mathrm{PR}=$ Procurement; $\mathrm{CM}=$ Construction Management; $\mathrm{O}=$ Organizational=Process.

The Pearson correlation coefficient at a confidence level ( $C L=95 \%)$ was conducted to compute the correlation between the potential identified strategies. The findings (Table 14) have presented the statistically positive correlation at a significant value of $(p<0.01$ and $p<0.05)$ in attaining a SC.

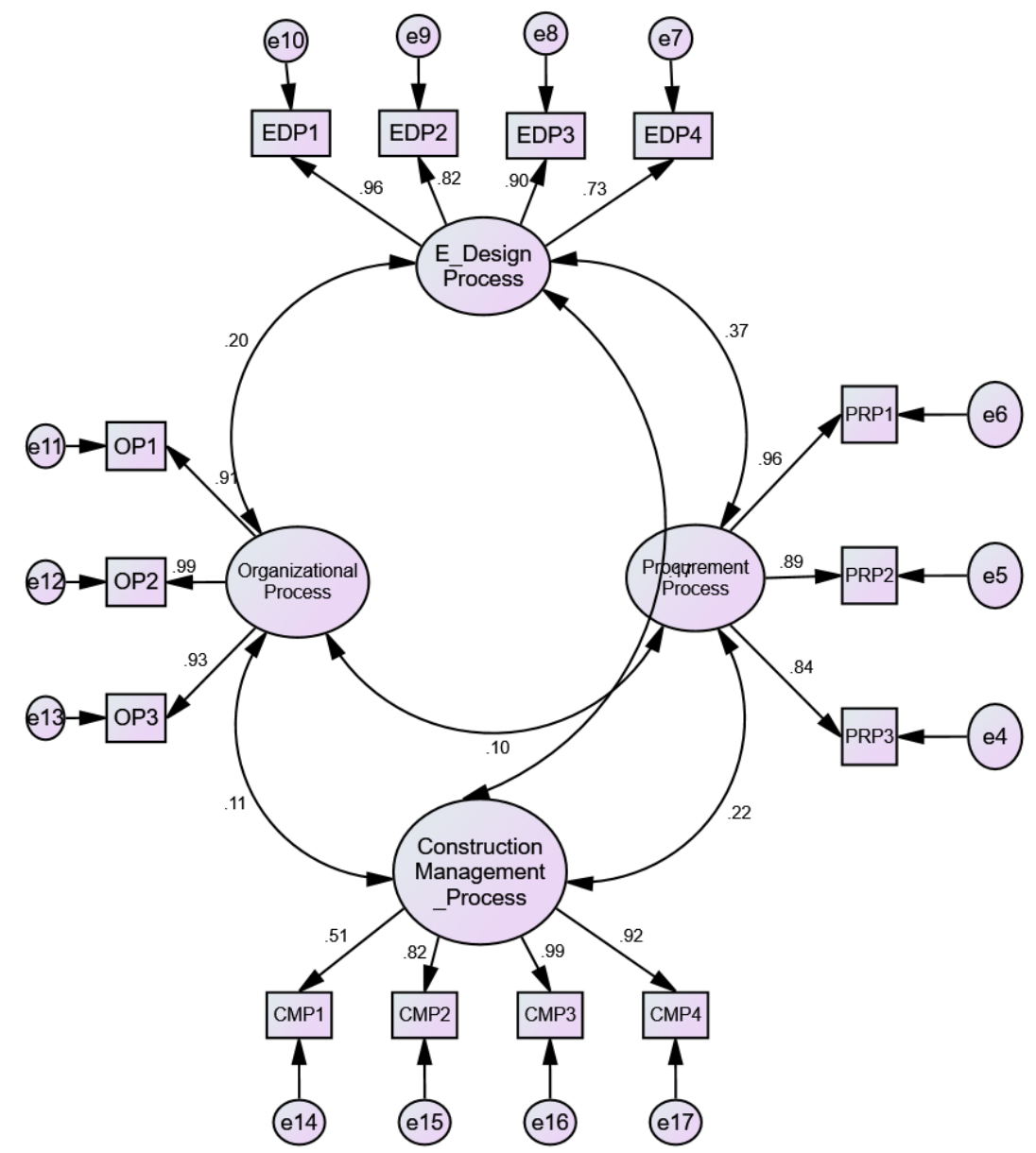

Figure 2. The Path Diagram Relationship between Variables; Source: (Researchers). 


\subsection{Structural Equation Modelling}

The structural equation modeling (SEM) technique was chosen to test the theories or model between a construct's relative observed and latent variables. The structural model was built based on literature and correlation as defined in the study's conceptual framework. Always SEM supports to identify the scope to which the collected sample data support the theoretical model. During data manipulation and processing using SPSS-AMOS 24, all variables in a construct were drawn and retrieved for processing. After naming as defined within the data set file, the path coefficient for correlation and regression of a latent variable to an observed variable was drawn. Errors associated with observed variables were established, followed by determining the correlation covariance between latent variables. The path diagram (Figure 2) was drawn to indicate the positive relationships between each latent variable.

Furthermore, the structural model framework (Figure 3) has been presented to indicate the standardized estimates values between latent variables in attaining sustainable competitiveness. The model result has provided the model fit statistics indices with $(\chi 2$ /degree of freedom $=314.1 / 120=$ 2.62 within acceptable threshold of $<3$ ); Room mean square error of approximation (RMSE) $=0.049$ (acceptable threshold $<0.08$ ); [Adjusted Goodness Fit of Index $(\mathrm{AGFI})=0.939$ and Comparative fit index (CFI) $=0.927$ both with acceptable threshold value $>0.9$ )]; and Normed Fit Index $(\mathrm{NFI})=0.949$ (threshold value $>0.9$ ). The Structural model framework has signified the significant positive relationships between variables. It is observed from the framework that there is a good relationship between strategic process variables in contributing to attaining sustainable competitiveness of SMLC.

However, the findings (Table 13) have indicated four predictors that had attained a reasonably and explained a significant relationship between defined variables. Thus, the findings imply that all four constructs of the identified strategies (engineering design, procurement, construction management, and organizational processes) have been found to possess a positive statistically significant contribution in achieving a sustainable competitive advantage intension to SMLC in LDC.

Table 13. Unstandardized Regression Weight.

\begin{tabular}{|c|c|c|c|c|c|c|c|}
\hline \multirow{3}{*}{ Decision } & \multirow{3}{*}{ Path } & \multicolumn{6}{|l|}{ Coefficients } \\
\hline & & \multirow{2}{*}{ Strategic Model Process } & \multicolumn{2}{|c|}{ Unstandardized Coefficients } & \multirow{2}{*}{$\begin{array}{l}\text { Standardized Coefficients } \\
\text { Beta }\end{array}$} & \multirow{2}{*}{ T-Value } & \multirow{2}{*}{ Sig. } \\
\hline & & & B & Std. Error (SE) & & & \\
\hline Intension & $\begin{array}{c}<-- \\
\end{array}$ & E. Design & 0.228 & 0.060 & 0.353 & 13.794 & 0.000 \\
\hline Intension & $<---$ & Procurement & 0.091 & 0.085 & 0.096 & 11.067 & 0.003 \\
\hline Intension & $<---$ & Construction Management & 0.264 & 0.082 & 0.289 & 13.243 & 0.002 \\
\hline Intension & $<--$ & Organizational & 0.068 & 0.075 & 0.079 & 11.914 & 0.004 \\
\hline
\end{tabular}

Thus, Sustainable Competitiveness (SC) Model $=\left(\beta_{0}+\beta_{1}\right.$ EDesign $+\beta_{2}$ Procurement $+\beta_{3}$ Constuction.management + $\beta_{4}$ Organizatioanal) Processes $+\varepsilon$ :

Where $(\beta 1=0.228, \mathrm{p}=0.000 ; \beta 2=0.091, \mathrm{p}=0.003 ; \beta 3=0.264, \mathrm{p}=0.002, \beta 4=0.068 ; \mathrm{p}=0.004)$ and $\varepsilon=$ an error.

Table 14. Pearson Correlation between Strategic Processes.

\begin{tabular}{|c|c|c|c|c|c|c|c|c|c|c|c|c|c|c|c|}
\hline & & EDP1 & EDP2 & EDP3 & EDP4 & PRP1 & PRP2 & PRP3 & CMP1 & CMP2 & CMP3 & CPMP4 & OP1 & OP2 & OP3 \\
\hline EDP1 & $\begin{array}{l}\text { Pearson Correlation } \\
\text { Sig. (2-tailed) }\end{array}$ & 1 & & & & & & & & & & & & & \\
\hline EDP2 & $\begin{array}{l}\text { Pearson Correlation } \\
\text { Sig. (2-tailed) }\end{array}$ & $\begin{array}{l}.787^{* *} \\
0.000\end{array}$ & 1 & & & & & & & & & & & & \\
\hline EDP3 & $\begin{array}{l}\text { Pearson Correlation } \\
\text { Sig. (2-tailed) }\end{array}$ & $\begin{array}{l}.869^{* *} \\
0.000\end{array}$ & $\begin{array}{l}.715^{* *} \\
0.000\end{array}$ & 1 & & & & & & & & & & & \\
\hline EDP4 & $\begin{array}{l}\text { Pearson Correlation } \\
\text { Sig. (2-tailed) }\end{array}$ & $\begin{array}{l}.683^{* *} \\
0.000\end{array}$ & $\begin{array}{l}.695^{* *} \\
0.000\end{array}$ & $\begin{array}{l}.634^{* *} \\
0.000\end{array}$ & 1 & & & & & & & & & & \\
\hline PRP1 & $\begin{array}{l}\text { Pearson Correlation } \\
\text { Sig. (2-tailed) }\end{array}$ & $\begin{array}{l}.361^{* *} \\
0.000\end{array}$ & $\begin{array}{l}.327^{* *} \\
0.001\end{array}$ & $\begin{array}{l}.319^{* *} \\
0.001\end{array}$ & $\begin{array}{l}.351^{* *} \\
0.000\end{array}$ & 1 & & & & & & & & & \\
\hline PRP2 & $\begin{array}{l}\text { Pearson Correlation } \\
\text { Sig. (2-tailed) }\end{array}$ & $\begin{array}{l}0.148^{*} \\
0.001\end{array}$ & $\begin{array}{l}.204^{*} \\
0.004\end{array}$ & $\begin{array}{l}0.251^{*} \\
0.003\end{array}$ & $\begin{array}{l}0.219^{*} \\
0.001\end{array}$ & $\begin{array}{l}.446^{* *} \\
0.000\end{array}$ & 1 & & & & & & & & \\
\hline PRP3 & $\begin{array}{l}\text { Pearson Correlation } \\
\text { Sig. (2-tailed) }\end{array}$ & $\begin{array}{l}.302^{* *} \\
0.004\end{array}$ & $\begin{array}{l}0.662 * * \\
0.002\end{array}$ & $\begin{array}{l}0.179 * \\
0.087\end{array}$ & $\begin{array}{l}.210^{* *} \\
0.004\end{array}$ & $\begin{array}{l}.826^{* *} \\
0.000\end{array}$ & $\begin{array}{l}.402^{* *} \\
0.000\end{array}$ & 1 & & & & & & & \\
\hline CMP1 & $\begin{array}{l}\text { Pearson Correlation } \\
\text { Sig. (2-tailed) }\end{array}$ & $\begin{array}{l}.333^{* *} \\
0.001\end{array}$ & $\begin{array}{l}.350^{* *} \\
0.000\end{array}$ & $\begin{array}{l}.260^{* *} \\
0.005\end{array}$ & $\begin{array}{l}.244^{*} \\
0.014\end{array}$ & $\begin{array}{l}.277^{* *} \\
0.005\end{array}$ & $\begin{array}{l}0.247 \\
0.014 *\end{array}$ & $\begin{array}{l}.225^{*} \\
0.224^{*}\end{array}$ & 1 & & & & & & \\
\hline CMP2 & $\begin{array}{l}\text { Pearson Correlation } \\
\text { Sig. (2-tailed) }\end{array}$ & $\begin{array}{l}.221^{*} \\
0.027\end{array}$ & $\begin{array}{l}0.292^{*} \\
0.055\end{array}$ & $\begin{array}{l}0.231 * \\
0.079\end{array}$ & $\begin{array}{l}0.273^{*} \\
0.085\end{array}$ & $\begin{array}{l}0.480 * * \\
0.006\end{array}$ & $\begin{array}{l}0.101 \\
0.319\end{array}$ & $\begin{array}{l}0.013 \\
0.185\end{array}$ & $\begin{array}{l}.633^{* *} \\
0.000\end{array}$ & 1 & & & & & \\
\hline CMP3 & $\begin{array}{l}\text { Pearson Correlation } \\
\text { Sig. (2-tailed) }\end{array}$ & $\begin{array}{l}0.227^{*} \\
0.009\end{array}$ & $\begin{array}{l}0.109 \\
0.279\end{array}$ & $\begin{array}{l}0.121 \\
0.230\end{array}$ & $\begin{array}{l}0.158 \\
0.117\end{array}$ & $\begin{array}{l}0.187 \\
0.062\end{array}$ & $\begin{array}{l}0.047 \\
0.646\end{array}$ & $\begin{array}{l}0.116 \\
0.250\end{array}$ & $\begin{array}{l}.506^{* *} \\
0.000\end{array}$ & $\begin{array}{l}.814^{* *} \\
0.000\end{array}$ & 1 & & & & \\
\hline CMP4 & $\begin{array}{l}\text { Pearson Correlation } \\
\text { Sig. (2-tailed) }\end{array}$ & $\begin{array}{l}0.128 \\
0.206\end{array}$ & $\begin{array}{l}0.078 \\
0.441\end{array}$ & $\begin{array}{l}0.041 \\
0.685\end{array}$ & $\begin{array}{l}0.066 \\
0.514\end{array}$ & $\begin{array}{l}0.084 \\
0.404\end{array}$ & $\begin{array}{l}0.087 \\
0.389\end{array}$ & $\begin{array}{l}0.021 \\
0.838\end{array}$ & $\begin{array}{l}0.102 \\
0.310\end{array}$ & $\begin{array}{l}0.122 \\
0.227\end{array}$ & $\begin{array}{l}0.134 \\
0.183\end{array}$ & 1 & & & \\
\hline OP1 & $\begin{array}{l}\text { Pearson Correlation } \\
\text { Sig. (2-tailed) }\end{array}$ & $\begin{array}{l}0.088 \\
0.384\end{array}$ & $\begin{array}{l}.289^{* *} \\
0.004\end{array}$ & $\begin{array}{l}0.157 \\
0.119\end{array}$ & $\begin{array}{l}0.159 \\
0.113\end{array}$ & $\begin{array}{l}0.004^{* *} \\
0.961\end{array}$ & $\begin{array}{l}0.099 \\
0.328\end{array}$ & $\begin{array}{l}0.088 \\
0.384\end{array}$ & $\begin{array}{l}0.090 \\
0.371\end{array}$ & $\begin{array}{l}-0.015 \\
0.882\end{array}$ & $\begin{array}{l}-0.037 \\
0.715\end{array}$ & $\begin{array}{l}-0.068 \\
0.502\end{array}$ & 1 & & \\
\hline
\end{tabular}




\begin{tabular}{|c|c|c|c|c|c|c|c|c|c|c|c|c|c|c|c|}
\hline & & EDP1 & EDP2 & EDP3 & EDP4 & PRP1 & PRP2 & PRP3 & CMP1 & CMP2 & CMP3 & CPMP4 & OP1 & OP2 & OP3 \\
\hline \multirow{2}{*}{ OP2 } & Pearson Correlation & 0.099 & $.250^{*}$ & 0.123 & 0.067 & -0.032 & 0.087 & -0.050 & -0.089 & 0.046 & 0.024 & 0.016 & $.283^{* *}$ & 1 & \\
\hline & Sig. (2-tailed) & 0.328 & 0.012 & 0.224 & 0.511 & 0.748 & 0.389 & 0.624 & 0.381 & 0.649 & 0.815 & 0.871 & 0.004 & & \\
\hline \multirow{2}{*}{$\mathrm{OP} 3$} & Pearson Correlation & 0.075 & 0.189 & 0.112 & 0.054 & -0.042 & 0.014 & 0.000 & -0.105 & -0.037 & -0.013 & -0.060 & $.368^{* *}$ & $.691^{* *}$ & 1 \\
\hline & Sig. (2-tailed) & 0.461 & 0.059 & 0.265 & 0.005 & 0.679 & 0.889 & 0.997 & 0.299 & 0.717 & 0.900 & 0.552 & 0.000 & 0.000 & \\
\hline
\end{tabular}

Note: **. Correlation is significant at the 0.01 level (2-tailed); *. Correlation is significant at the 0.05 level (2-tailed).

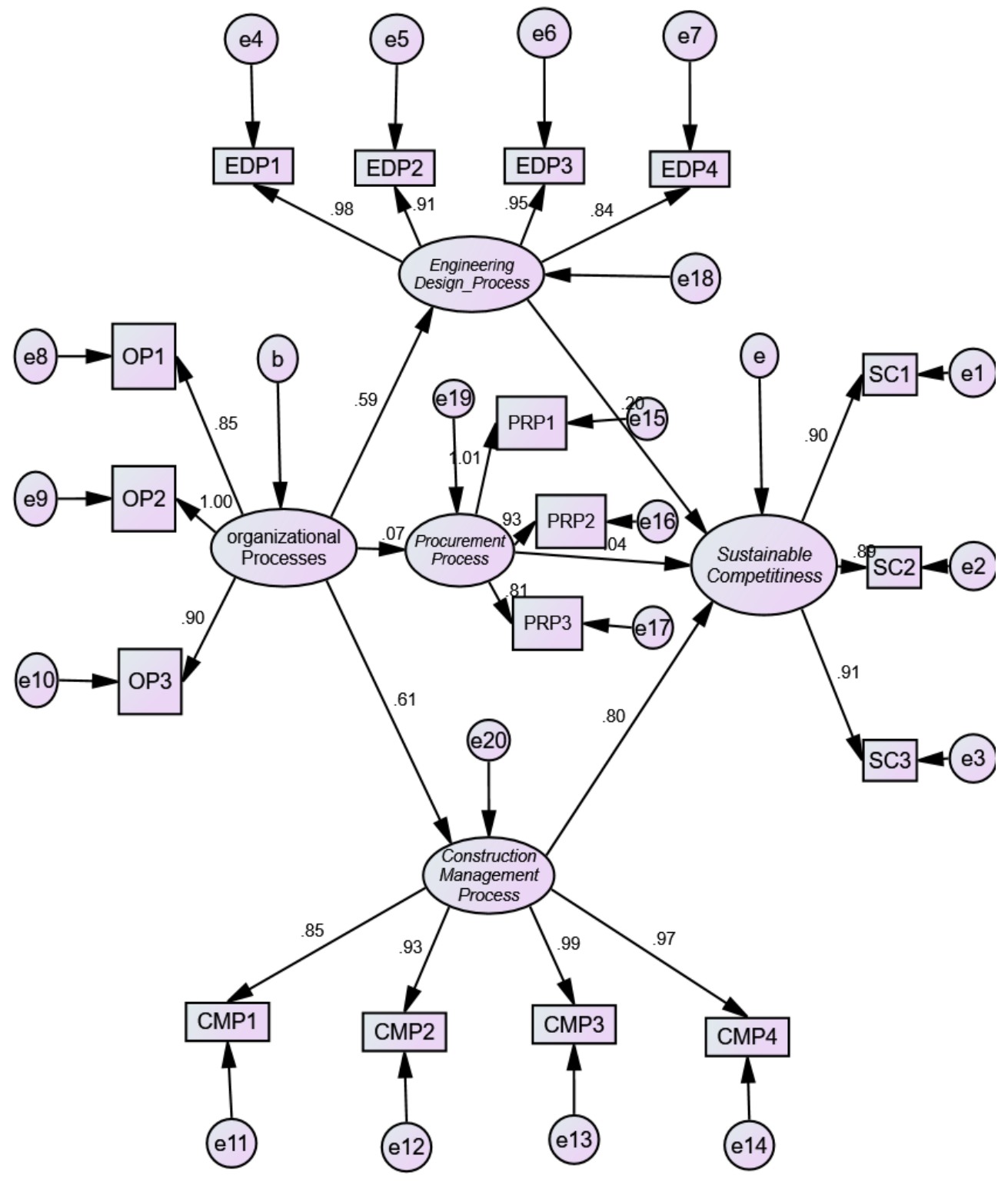

Figure 3. A Structural Model Framework of Standardized Estimates.

\section{Discussions and Implication}

This study aims to contribute to the body of knowledge on a business re-engineering process of small and medium local contractors. Specifically, the study scrutinizes diverse strategic construction processes that can envisage sustainable competitiveness within a domestic competitive market environment. As explained below, the study's empirical findings have acknowledged that the most forgotten (organizational processes) have shown a significant contribution similar to construction core processes (engineering design, procurement, and construction management) in attaining sustainable competitiveness. The findings suggest that when strategic organizational processes are intermingled with core construction processes, it produces positively and a significant effect in achieving sustainable competitiveness, as explained below:

a) Engineering Design (ED) Processes

In any construction project, engineering design and construction production processes are separated and executed by separate and independent team parties, namely contractor and consultant, as designers working with different interests. However, sometimes the construction process can necessitate 
simultaneous with the design process due to various changes to be accommodated. Thus, to attain a good ED, a strategic design is considered necessary. Competent and skilled design team, assigning enough design resources, mobilization of complete client and customer's needs, and working in collaboration with other related sections can always assist in reducing the design variation error (DVE), which suffered from a slid milestone, cost, and time overrun with less quality and low value for money as a substantial factor for a Sustainable Competitiveness. It was noted that the strategic design process needs careful consideration to avoid a design variation as a deviation from correct and acceptable practice. Muhammad et al., 2015 indicated that design error and design changes contribute to about $65 \%$ and $30 \%$, respectively, of variation [71]. Therefore, it is distinguished that poor construction drawings, use of inexperienced and poor collaboration among designs experts, failing to accommodate scope changes done by clients, omission in designs, and lack of adequate design resources are the prominent factors for design-error-variation encumber a SC and compromises successful completion of construction projects. Thus, it is envisaged to incorporate the strategic design processes to attain a SC.

b) Procurement Process (PP)

Most SMLC under domestic competitive market have failed to win and acquire massive construction projects because of the imperfect procurement process (PP) such as bidding strategy. Most foreign firms are considered to possess more competitive advantages, including a better procurement strategic process of low bidding, which leads them to win most of the bids [72]. Therefore, SMLC should strategize on the bidding process by reducing unnecessary costs resulting in high bidding costs. Firms must bid at a reasonable price that considers a low-profit margin which can influence winning the bid. Thus, PP has been noted as a holistic and systemic approach to completing all construction projects phases. It has remained significant to SMLC from its best practice of focusing on the quality service and materials acquisition, supply and management procedures that hire an integrated method and technique to manage the processes, relationships, and consequences jointly with the suppliers [73]. Different PP intends to affect construction project performance that remains noteworthy to enhance successful project completion hence SC. Accordingly, various procurement strategic process that includes enforcing to abide by ethics and code of conduct such as procurement control, low bidding, assurance and integrity, adoption of an electronic-e-tendering system to reduce a bidding cycle and reviewing the conflicting procurement policies \& regulations to avoid frequent conflicts and disputes among different actors, cost and schedule overruns in projects that can hamper attaining a SC. Thus, it is recommended to implement the strategic procurement process to achieve a SC of SMLC.

c) Construction Management Process (CMP)

$\mathrm{CMP}$ is an overall administration process encompassing planning, organizing, controlling, effective allocation, utilization supervision of the overall construction project's resources to attain sustainable competitiveness in terms of reasonable operative time, minimum possible cost, and good quality with value for money (VFM). CMP entails ensuring the adoption of IT and BIM, employing competent and skilled human resources, ensuring effectively and efficiently allocation, utilization, and management of all construction project's resources such as finance, schedule, material, equipment, etc. since project's inception to completion, human resource management, provision of certified training to capacitate employees, financial capability as well as ensuring a joint venture with other foreign firms to ensure successful project delivery, hence a SC as explained hereunder: -

\section{i. Certified Training to Capacitate Human resource}

Provision of certified Training is one of the CM strategic processes since it enhances knowledge sharing to an employee on different aspects. Training not only acts as recognition and rewards to an employee but also serves as a firm's competitive advantage. Thus, lack of knowledge and skills to firm owners and stakeholders has made unsustainable competitiveness of SMLC. [74] Owed that, since training constitutes strategies, policies, procedures, lessons, and tools for employee's knowledge and skills acquisition can enhance good practice that produces a significant relationship with firm's quality productivity for a Sustainable Competitiveness. Moreover, an example of Chinese firms becoming competitive was supported by talented and skilled human resources who acquire competence and knowledge through different programs before being sent to international construction projects overseas [75]. Therefore, on-job training, seminars, and workshops must be enforced by SMLC and certified by the government.

\section{ii. Effective Resources Utilization}

Resources utilization is among the most CM strategic process towards attaining competitive advantages for SC. Resources include skilled workforce, finance, technology, equipment, materials, environment, and fixed assets such as land, real estate, and leadership. Other resources such as fixed assets can acts as collateral security for the firm when applying for a loan from financial institutions [64]. Thus, SMLC's resources should be thoroughly maintained, adequately allocated, and effectively utilized for a SC.

iii. Finance Capability and Partnership

Financial capabilities and partnership of and between SMLC are acknowledged to correlate in attaining the firm's sustainable competitive advantage directly. A study by Tabassi, A. et al., 2011 reinforced that financial ability is among the most preferential business strategies and the topmost ranking factor and an essential ingredient strategy of competitiveness. Thus, Seung H et al.(2010) emphasized the financial institutions, including banks and insurance agencies, to recapitalize the firms to attain competitive advantage for SC [76].

iv. Strategic alliance and Joint Venture

Strategic alliance and the joint venture were recommended 
among the CM strategic process to enhance skills and knowledge. Working in collaboration with foreign firms has been proved to facilitate attaining skills, expertise, resource sharing, and technology transfer to create a competitive advantage. A joint venture involves a legally binding agreement (s) to share the combined resources, competencies, and capabilities to achieve a competitive advantage in the competitive market. The government should enforce laws on a joint venture in some public projects to assist SMLC in learning different strategies adopted by experienced foreign firms that help in problem-solving [77] and attain a SC.

d) Organizational Strategic Process (OSP)

Almost every firm or organization struggles to attain a good performance as a competitive advantage for a SC and development. Therefore, they are obliged to produce a dramatic improvement not only to compete and prosper but also to survive. Thus, construction firms are advised to reflect their strategic organizational (both functional and project) processes to remove the non-value strategic processes and remain with potential one. OP is a set of operations and practices that allow a consistent and resilient management process performance throughout the organization and provide the basis for cumulative, long-term benefits. Therefore, most organizational processes sometimes act as a construction management process that can be classified into planning, administration, and control process. In this study, strategic administrative functions such as developing an effective organization structure, capacitating the human resource through training, and maintaining the low operational cost of the firm were mentioned to facilitate a SC. Organizational Structure is defined as the recognized system that defines the line of organization of tasks and reports relationships that control, coordinate, and encourage and motivate workers to cooperate to achieve an intended organization's objectives. A well-defined organizational structure can enhance continuity, time, resources, and quality control in the functional disciplines to attain a SC [78]. Thus, OSP needs to be effectively realized for the sustainable competitiveness of SMLC.

\section{Conclusion}

Sustainable competitiveness (SC) is a critical challenge to most SMLC since it is affected by different problems and dynamics such as lack of resources, non-value processes, poor management skills, ineffective performance with low productivity, and lack of government strategies and policies. However, for many decades, challenges have demonstrated a less competitive atmosphere of SMLC in the domestic market. The little competitive environment has created a miserable, confusing, and even no operational engagement in any global or international construction projects. Thus, a construction firm's sustainable competitiveness (SC) is currently a hot topic in LDC since it is affected by many factors. Despite that, many studies on construction firm's competitiveness have mainly concentrated on construction core processes (design, procurement, and construction management) strategies and leaving strategic organizational processes untouched. Scores of the findings have revealed fourteen (14) potential strategic processes from both (construction core and administrative) processes to have a significant positive effect on sustainable competitiveness. Thus, it can be concluded from the findings that the strategic organizational process also has a significant positive contribution to attain a SC. Therefore, to realize a drastic change as a business re-engineering process outcome, SMLC should invest in value strategic processes rather than resource strategies. Adopting re-engineering to itemize the potential organizational strategic process as value activities to enhance a sustainable competitiveness and guarantee the gratification of the client and other shareholders' needs is of utmost importance.

Moreover, it can be drawn from the study findings that the re-engineering process on construction business is necessary for SMLC to identify the value strategic process for attaining a performance drastic change and hence a SC. In addition, SMLC needs to adapt/adopt the building technology to easier both construction core and organizational processes. Conversely, the study also proposes a joint venture with foreign firms in construction projects to attain a competitive advantage. Thus, to the best of information, this finding may be one of the most comprehensive studies that provide the insight and initial evidence to advance the knowledge in the construction industry and contribute and implication for researchers and stakeholder's construction industry of LDC. The study has proved the importance of focusing on reengineering processes, specifically organizational processes, to attain improved performance and a SC. Furthermore, CI policymakers should also play an essential role in communicating and promoting the organizational processrelated strategies benefits to SMLC improved competitiveness. Information and training programs should provide a vibrant and clear message about the OSP and its significant effects.

\section{Study Limitations and Direction for Future Research}

This study was limited to adopt the BPR to develop a model of strategic construction processes SMLC's sustainable competitiveness in LDC, taking Tanzania as a case study. Thus, the study findings cannot be generalized. Otherwise, it can only be considered significant to construction firms distinguishing similar characteristic environments with those of LDC. However, future research is recommended for modeling the effects of construction technology-related strategies in facilitating construction business re-engineering processes for SMLC.

\section{Data Availability}

The data collected for this can be accessible only upon request. 


\section{References}

[1] UN, "LDCs at a glance/Department of economics and Social Affairs," $2020 . \quad$ [Online]. Available: https://www.un.org/development/desa/dpad/least-developedcountry-category/ldcs-at-a-glance.html. [Accessed 6Th May 2020].

[2] Tesha, D. N. et al, "Growth Trend of Local Building Contractors for the Period of 2005-2015 in Dar Es Salaam, Tanzania," International Research Journal of Engineering and Technology (IRJET), vol. 4, no. 7, pp. 2082-2101, 2017.

[3] CIOB, "The Real Face of Construction 2020: Socio-Economic Analysis of the True Value of The Built Environment," Chartered Institute of Building (CIOB), UK, 2020.

[4] Lung'aho, C. \& Omagwa, J., "Working capital management and profitability of firms listed underconstruction and allied sector at the Nairobi securities exchange, Kenya," International Journal of Scientific and Education Research, vol. 02, no. 04, pp. 43-63, 2018.

[5] Oyewobi, O. et. al., "Competitiveness of construction organisations in South Africa," in Construction Research Congress, Conference Paper · May 2014, 2014.

[6] Jorge, L. et al., "The sustainability of the construction industry in Sub-saharan Africa: some new evidence from recent data," Procedia Engineering, no. 172, p. 657 - 664, 2017.

[7] A. Elkhalifa, "The Construction \& Building Materials Industries for Sustainable Development in Developing Countries: Appropriate and Innovative Local Building Materials and Technologies for Housing in the Sudan," 2020. [Online]. Available:

https://core.ac.uk/download/pdf/9412855.pdf. [Accessed 2nd June 2020].

[8] A. a. C. K. Windapo, "The South African Construction Industry: Perceptions of key Challenges Facing its Performance Development and Growth," J. of Constr. in Dev Countries, vol. 18, no. 2, pp. 6-6, 2013.

[9] Degu, S. et al., "Assessing The Effect of Business Process Reengineering on Organizational Performance: A Case Study Of Bureau Of Finance And Economic Development (Bofed), Oromia Regional State, Ethiopia," International Refereed Research Journal, vol. 4, no. 1, pp. 115-123, 2013.

[10] N. Isaga, "Entrepreneurship and the growth of SMEs in the Furniture Industry in Tanzania," 2012. [Online]. Available: https://research.vu.nl/files/42212399/chapter\%20all\%20chapt ers.pdf. [Accessed 8 June 2020].

[11] UN, "UNCTAD Multi-year Expert Meeting on Trade, Services and Development," UNCTAD, Tanzania, 2018.

[12] Bauchet, J. and Morduch, J, "Is micro too small? Microcredit vs. SME finance," World Development, vol. 43, p. 288-297, 2013.

[13] Yahya, M. and Mutarubukwa, P., "Capacity Of Tanzanian Micro, Small And Medium Enterprises (Mmses) in Tapping the Business Opportunities in the East African Community," Business Education Journal, pp. 1-20, 2015.

[14] Kyssima, E. H. et al, "Profit Maximization Strategies Employed by the Small and Medium SizeBuilding Contractors in Dar-Es-Salaam, Tanzania," International Journal of
Engineering and Management Research, vol. 10, no. 1, pp. 92-110, 2020.

[15] Safa, M et al., "Classification of Construction Projects," International Journal of Civil, Environmental, Structural, Construction and Architectural Engineering, vol. 9, no. 6, pp. 721-729, 2015.

[16] CRB, "Classification of contractors," 09 August 2020. [Online]. Available: http://www.crb.go.tz/classification-contractors.

[17] Kazungu, I. et al, "Improving Livelihoods through Micro and Small Agribusiness Enterprises: Analysis of Contributions, Prospects and Challenges of Nursery Gardens in Arusha Tanzania," International Journal of Business Management, vol. 6, no. 9, 2014.

[18] Yahya, M. and Mutarubukwa, P., "Paper Title: Capacity Of Tanzania Micro, Small And Medium Enterprises (MMSES) In Tapping The Business Opportunities In The East African Community," Business Education Journal, vol. 1, no. 1, pp. 121, 2015.

[19] Sexton, M. and Barrett, P., " Approriate innovation in small construction firms," Construction Management and Economics, vol. 21, no. 6, p. 623-633, 2003.

[20] Muhegi, B. and Malongo, "Globalisation: A Challenge to Developing Countries." in Paper Presented at International Symposium on Globalisation and Construction," Bangkok, Thailand, 2004.

[21] Kavishe, N. et al., "Public-private partnerships in Tanzanian affordable housing schemes_Policy and regulatory issues, pitfalls and solutions," Built Environment Project and Asset Management, pp. 1-12, 2019.

[22] H. Momade, "Brief Perspective of Kenya's Current Economy \& Construction Growth," 2020. [Online]. Available: https://www.academia.edu/6728850/Short_Summary_of_Ken yas_Construction_Growth_and_Development_Plans. [Accessed 4th May 2020].

[23] Ofori, G. and Toor, S. R, " Leadership and construction industry development in developing countries," Journal of Construction in Developing Countries, vol. 17, no. 1, pp. 1-21, 2012.

[24] URT, "THE PUBLIC PROCUREMENT ACT, 2011," THE UNITED REPUBLIC OF TANZANIA, Dar es Salaam, 2011.

[25] URT, "Construction Industry Policy (CIP) Implementation," URT-Ministry of works, Transport and Communication, Dar es Salaam, Tanzania, 2015.

[26] Serpell, A. and Diaz, J., "Linking central business processes of construction companies with the performance of construction operations: a preliminary exploration," Procedia Engineering, vol. 164 , p. $376-382,2016$.

[27] Haik, Y. and Tamer Shahin, T., Engineering Design Process, UK: CENGAGE Learning, 2010.

[28] Musangi, P. S. et al., "Critical success factors in library reengineering: a case of academic libraries in Kenya," Global Knowledge, Memory and Communication, vol. 68, no. 6/7, pp. 534-549, 2019.

[29] Weng L. E. and Alshawi, M., "Critical Success Factors for ETendering Implementation in Construction Collaborative Environments: People and Process Issues," Journal of Information Technology in Construction, vol. 14, pp. 98-109, 2009. 
[30] lveskoski, O. and Niittymaki, O., Construction Management: Study Book, Finland: Hame University of Applied Sciences, 2015 .

[31] Caralli, R. A. et al., CERT Resilience Management Model CERT-RMM: A Maturity Model for Managing Operational Resilience, USA: Addison-Wesley Educational Publishers Inc, 2016.

[32] G. Sudhakar, "The Role of IT in Business Process Reengineering," 2010. [Online]. Available: https://www.researchgate.net/publication/237050536_The_Ro le_of_IT_in_Business_Process_Reengineering. [Accessed 30Th June 2020].

[33] Thyagarajan, V., \& Khatibi, A., "BPR - A tool for managing the change," The Journal of Human Ecology, vol. 15, no. 1, pp. 57-61, 2004.

[34] Hammer, M., \& Champy, J., Re-engineering the Corporation, London: Nicholas Brealy, 1993.

[35] Davenport, T \& Short, J., "The new industrial engineering: Information technology and business process redesign," Sloan Management Review, pp. 11-17, 1990.

[36] Habi, M. N and Wazir, M. I., "Role of Education and Training in the Successful Implementation of Business Process Reengineering: A case of Public Sector of Khyber PakhtunKhwa (KPK)," World Journal of Social Sciences, vol. 2, no. 2, pp. $172-185,2012$.

[37] Shodhgang, "Chapter -1 Introduction-Shodhgang," 2008. [Online]. Available: http://shodhganga.inflibnet.ac.in/jspui/bitstream/10603/19490 0/6/06_chapter\%201.pdf. [Accessed 25th June 2020].

[38] O. El-Sawy, "Redesigning Enterprise Processes For Ebusiness", McGraw Hill Higher Education, 2001.

[39] M. Pryor, "Business Process re-engineering-Strategy and organization," $2020 . \quad$ [Online]. Available: https://www.referenceforbusiness.com/management/BunComp/Business-Process-Reengineering.html. [Accessed 1st May 2020].

[40] D. Homeas, "Business Process Reengineering And Erp Essay," $2014 . \quad$ [Online]. Available: https://www.bartleby.com/essay/Business-Process-

Reengineering-And-Erp-P3GLYP5Z9CXW. [Accessed 1810 2019].

[41] Sidwell, A. et al., "Reengineering the Construction Delivery Process, Report and Case Studies, Construction Industry Institute Australia," 2002. [Online]. Available: www.ciia.qut.com. [Accessed 299 2019].

[42] M. Urbaniec, "Sustainable Competitiveness. Opportunities and Challenges for Poland's Economy," Environmental policy and management, vol. 4, no. 59, pp. 35-51, 2016.

[43] Flanagan. R. et al., "Competitiveness in construction: a critical review of research," Construction Management and Economics, vol. 25, no. 9, pp. 989-1000, 2007.

[44] Flanagan, R. et al, "Measuring Construction Competitiveness in Selected Countries, Final Report," School of Construction Management and Engineering, the University of Reading, England, 2005.

[45] Balkyte, A and Tvaronavičienè, M., "Perception of
Competitiveness in the Context Of Sustainable Development: Facets of "Sustainable Competitiveness"," Journal of Business Economics and Management, vol. 11, no. 2, p. 341-365, 2010.

[46] K. Schwab, "The Global Competitiveness Index 2009-2010: Contributing to Long-Term Prosperity amid the Global Economic Crisis, in The Global Competitiveness Report 2009-2010. Geneva: World Economic Forum, 3-47," 18 June 2020. [Online]. Available: http://www.weforum.org/pdf/GCR09/GCR20092010fullreport .pdf.

[47] W. Lu, "A system for assessing and communicating contractors' competitiveness. Doctoral dissertation," The Hong Kong Polytechnic University, China, 2006.

[48] W. Lu, "A system for assessing and communicating contractors' competitiveness, thesis submitted to the," Department of Building and Real Estate, the Hong Kong Polytechnic University, Hong Kong, 2006.

[49] WEF, "Global Competitiveness Report 2013-2014," World Economic Forum, 2013.

[50] Martin, R. et al, Regional competitiveness, New York: Routledge, 2006.

[51] S. Garelli, IMD World Competitiveness Yearbook 2009: International Institute for Management Development. 21st. Ed. 543 p, Lausanne, 2009.

[52] M. Porter, Competitive Strategy: Techniques for Analyzing Industries and Competitors, New York/Collier Macmillan, London: Free Press, 1980.

[53] Barney J., et. al, "The Resource-based View of the Firm: Ten Years after 1991," Journal of Management, vol. 27, no. Pergamon, pp. PP. 625-641, 2001.

[54] Porter; Schendel, D, "Competitive organizational behavior: toward an organizationally: based theory of competitive advantages," Strategic Management Journal, vol. 15, pp. pp. $1-5,1994$

[55] WCY, World Competitiveness Yearbook, IMD Laousanne, Switzerland: IMD Laousann, 2002.

[56] Porter, Competitive Strategy: Techniques for Analysing Industries and Competitors, New York: Free Press, 1985.

[57] Henny, A. and Mohammed, F., "Improving skill's strategies of Indonesian construction labours to have global competitiveness," International journal of civil and structural engineering, vol. 3, no. 1, 2012.

[58] Wang, G., \& Yang, J, "Business Development Strategy and Australian Construction Industry," International Journal for Construction Marketing, vol. 2, no. 1, 2011.

[59] Abd Ghani. et, al, "Critical Internal and External Factors that affect Firms Strategic Planning," International Research Journal of Finance and Economics, vol. 51, pp. 50-58, 2010.

[60] Iyagba, R., \& Ojuola, J, "An Overview of the Causes of Collapse of some Construction Firms," The Journal of the Federation of Construction Industry, 19, vol. 19, no. 2, 2004.

[61] Kehinde, J. O., \& Mosaku, T. O, "An empirical study of assets structure of building construction contractors in Nigeria, Engineering," Construction and Architectural Management. vol. 13, no. 6, pp. 634-644, 2006. 
[62] Tabassi, A. et al., "Training, motivation and teamwork improvement: The case of construction firms," African Journal of Business Management, vol. 5, no. 14, pp. 5627$5636,2011$.

[63] Fajar. S. H, "Strategies for Small-Medium scale contractor Performance improvement in ASEAN competitive market," Procedia Engineering, vol. 12, no. 2017, pp. 387-395, 2017.

[64] CRB, "Contractors Registration Board," 2020. [Online]. Available: http://www.crb.go.tz/. [Accessed 26 April 2020].

[65] Taherdoost, H., "Determining Sample Size: How to Calculate Survey Sample Size," International Journal of Economics and Management Systems, vol. 2, pp. 237-239, 2017.

[66] J. Nguli, 2017. [Online]. Available: (2017). Re: How to score a likert Scale? Retrieved from: https://www.researchgate.net/post/How_to_score_a likert Sc ale/59efe557eeae39563907ec80/citation/download. [Accessed 29Th May 2020].

[67] Gliem, J. A. and Gliem, R. R, "Calculating, Interpreting, and Reporting Cronbach's Alpha Reliability Coefficient for Likert-Type Scales," in Midwest Research-to-Practice Conference in Adult, Continuing, and Community Education, Columbus, OH, 2003.].

[68] K. Samaraweera, "What should be ideal KMO value for factor analysis?," $2020 . \quad$ [Online]. Available: https://www.researchgate.net/post/What_should_be_ideal_K MO_value_for_factor_analysis/5ebee64c5f9cc675395089d4/c itation/download.. [Accessed 31Th May 2020].

[69] I. Shifidi, "Small Builders in the Namibian Construction Sector: Opportunities, Challenges And Support Strategies," 2012. [Online]. Available: https://econrsa.org/system/files/workshops/papers/2012/shifidi -small-builders.pdf. [Accessed 234 2019].

[70] Zaini, A. et al., "The Effect of Human Resource Management Practices on Business Performance among Private Companies in Malaysia," International Journal of Business and Management, vol. 46, no. (6), pp. 65-72, 2009.
[71] Tzafrir, "A Universalistic Perspective for Explaining the Relationship between HRM Practices and Firm Performance at Different Points in Time," Journal of Managerial Psychology, vol. 21, no. 2, pp. 109-130, 2006.

[72] Lu, W. et al., "Strengths, weaknesses, opportunities, and threats analysis of Chinese construction companies in the global market," J. Manage. Eng, vol. 25, no. 4, pp. 166-176, 2009.

[73] Y. Kunhui and Tekka, R. S, "A Prioritization Model of Strategies for Small and Medium Firms in Less-Developed Countries: A Tanzania Case," Advances in Civil Engineering, pp. 1-23, 2020.

[74] Abdulwahed, M. \& Hasna, M., "The Role of Engineering Design in Technological and 21st Century Competencies Capacity Building: Comparative Case Study in the Middle East, Asia, and Europe," Sustainability, pp. 1-23, 2017.

[75] P. Prudon, "Confirmatory factor analysis as a tool in research using questionnaires: a critique," Comprehensive Psychology, vol. 4, no. 10, pp. 1-18, 2015.

[76] Muhammad, N. Z et al, "Causes of variation order in building and civil engineering projects in Nigeria," Jurnal Teknologi (Sciences \& Engineering), vol. 77, no. 16, pp. 91-97, 2015.

[77] G. Kikwasi, "Causes and Effects of Delays and Disruptions in Construction Projects in Tanzania, in: Chileshe, N., Rofe, M., Rameezdeen, R. et al (Eds.)," in Proceedings of the 6th International Conference and Workshop on Built Environment Developing Countries 'Fragmented Futures: the built environment in a volatile world', 4th - 5th December 2012, pp. 138-148, Adelaide, Australia, 2012.

[78] Zhao, Z. Y. and Shen, L. Y., "'Are Chinese contractors competitive in international markets?."," Construction Management and Economics,, vol. 26, no. 3, pp. 225-236, 2008. 